Juan Garrido, Francisco Vázquez, Fernando Morilla, Centralized multivariable control by simplified decoupling, Journal of Process Control, Volume 22, Issue 6, July 2012, Pages 1044-1062, ISSN 0959-1524,

http://dx.doi.org/10.1016/.jprocont.2012.04.008 (http://www.sciencedirect.com/science/article/pii/S0959152412000935)

\title{
CENTRALIZED MULTIVARIABLE CONTROL BY SIMPLIFIED DECOUPLING
}

\author{
Juan Garrido $^{\mathrm{a}^{*}, \text { Francisco Vázquez }^{\mathrm{a}} \text {, Fernando Morilla }}{ }^{\mathrm{b}}$ \\ ${ }^{a}$ Department of Computer Science and Numerical Analysis, University of Córdoba, \\ Campus de Rabanales, 14071, Córdoba, Spain \\ *Fax: (+34)957218729; e-mail: juan.garrido@uco.es \\ ${ }^{b}$ Department of Computer Science and Automatic Control, UNED, Juan del Rosal 16, \\ 28040, Madrid, Spain
}

\section{Introduction}

Most industrial processes have multiple variables in nature, and this fact increases as result of the high demand on product quality and the required energy integration. Multiinput multi-output (MIMO) systems consist of several measurement and control signals, which often present complicated couplings between them. To cope with this problem, control engineers traditionally use single-loop PID controllers because these controllers can be easily understood and implemented [1]. These decentralized approaches can work properly when the interactions in different channels of the process are modest [25]. However, a MIMO process can be much more difficult to control with strong interactions between the channels. Therefore, the decoupling performance obtained from traditional and well-established single-loop PID tuning technologies are not satisfactory. In fact, major leading controller manufactures rank the poor decoupling of multivariable systems as one of the principal control problems in the industry [6]. In these cases, a full matrix controller (centralized control) is advised. To design a centralized control, two different approaches are common in the literature: a decoupling network combined with a diagonal decentralized controller, or a pure centralized strategy.

Figure 1 shows the general decoupling control system, where $\mathrm{G}(\mathrm{s}), \mathrm{D}(\mathrm{s})$ and $\mathrm{C}(\mathrm{s})$ are the n-dimensional process matrix, the decoupler matrix and the diagonal control matrix, respectively. $\mathrm{D}(\mathrm{s})$ is designed to minimize the process interactions in such a way that the controller $\mathrm{C}(\mathrm{s})$ sees the apparent process $\mathrm{G}(\mathrm{s}) \cdot \mathrm{D}(\mathrm{s})$ as a set of $\mathrm{n}$ completely independent processes. This arrangement allows for independent control of the loops using single-input single-output (SISO) controllers.

\section{INSERT HERE FIGURE 1}

Over the years, decoupling control has been addressed in the literature $[1,6,7]$. Some decoupling schemes are static [8], and others are dynamic [9-14]. Static decoupling guarantees complete decoupling only for low frequencies, which may not be sufficient for a good performance. Dynamic decoupling reduces or eliminates the interactions in a wider range of frequencies.

Most decoupling approaches use the conventional decoupling scheme depicted in Figure 1. In this case, the design of the decoupler network for an $n \times n$ process is obtained from expression (1) generally by specifying $n$ elements of the decoupler $\mathrm{D}(\mathrm{s})$ 
or the $\mathrm{n}$ desired transfer functions of the apparent process $\mathrm{Q}(\mathrm{s})$, which is defined as the diagonal matriz $\operatorname{diag}\left(\mathrm{q}_{1}, \mathrm{q}_{2}, \ldots, \mathrm{q}_{\mathrm{n}}\right)$.

$\mathrm{D}(\mathrm{s})=\mathrm{G}^{-1}(\mathrm{~s}) \cdot \mathrm{Q}(\mathrm{s})$

The main problem of this methodology is the fact that the complexity of decoupler elements and apparent processes increases for high-dimensional MIMO processes, which may require model reductions. An alternative decoupling method, called inverted decoupling, maintains very simple apparent processes and decoupler elements independently of the system size [14]. In addition, inverted decoupling presents several practical advantages on implementation [15]. Nevertheless, the method also has an important disadvantage: because of stability problems, it cannot be applied to processes with multivariable right half plane (RHP) zeros, that is, RHP zeros in the determinant of the process transfer matrix G(s). In this case, the decoupling scheme of Figure 1 would be required despite its disadvantages.

On the other hand, Figure 2 represents a pure centralized control system with $\mathrm{K}(\mathrm{s})$ being the $n$-dimensional full matrix controller. $K(s)$ works as the only block to control the different measurement signals and to reduce the interactions. In recent years, several methodologies were developed for this design [16-23]. Most of them propose to find a $\mathrm{K}(\mathrm{s})$ such that the closed loop transfer matrix $\mathrm{G}(\mathrm{s}) \cdot \mathrm{K}(\mathrm{s}) \cdot[\mathrm{I}+\mathrm{G}(\mathrm{s}) \cdot \mathrm{K}(\mathrm{s})]^{-1}$ is decoupled over some desired bandwidth. This goal can be achieved if the open loop transfer matrix $\mathrm{G}(\mathrm{s}) \cdot \mathrm{K}(\mathrm{s})$ is diagonal. Therefore, these techniques are very similar to those used to design decoupler networks. The complexity of the resultant controller elements of $\mathrm{K}(\mathrm{s})$ can be very different depending on the methodology. For instance, in [19], a fulldimensional non-PID is obtained from a recursive least square optimization problem. In [20], an analytical decoupling control strategy is proposed on the basis of the $\mathrm{H}_{2}$ optimal performance specifications. Nevertheless, PID controllers have dominated applications for more than 60 years. They are preferred over more advanced controllers in practical applications unless PID controls cannot meet the specifications. Therefore, the resultant controller $\mathrm{K}(\mathrm{s})$ in several methodologies [16, 21, 22, 23] is a multivariable PID control.

\section{INSERT HERE FIGURE 2}

Although model predictive control (MPC) is becoming the standard technique to solve multivariable control problems in the process industry, several authors $[10,19,21]$ claim that MPC is mostly used on a higher level to provide setpoints to the PID controllers that are operating on the basic level. The MPC is operating in a supervisory mode with sampling times that are longer than the sampling times in the PID controllers at the lower level. Dealing with the interaction at the MPC level can be difficult because the bandwidths of the MPC loops are limited. Therefore, the centralized control using multivariable PID controllers or decoupler networks is an interesting alternative strategy in the process industry.

This work focuses on one of the most extended forms of conventional decoupling called simplified decoupling, in which $\mathrm{n}$ elements of the decoupler are set to unity. This approach received considerable attention in both control theory and industrial practice for several decades. However, like most other methodologies, it focuses on systems with two inputs and two outputs (TITO systems). In this case, the simplified decoupling 
$\mathrm{D}(\mathrm{s})$ is given by expression (2), obtaining the decoupled apparent process $\mathrm{Q}(\mathrm{s})$ in expression (3). The authors have found very few published works in which simplified decoupling is applied to processes that are larger than a $2 \times 2$ system; in cases where the system is larger than $2 \times 2$, the decoupler elements set to unity are always the diagonal ones as found using expression (4) [24].

$$
\begin{aligned}
& \mathrm{D}(\mathrm{s})=\left(\begin{array}{cc}
1 & -\frac{\mathrm{g}_{12}(\mathrm{~s})}{\mathrm{g}_{11}(\mathrm{~s})} \\
-\frac{\mathrm{g}_{21}(\mathrm{~s})}{\mathrm{g}_{22}(\mathrm{~s})} & 1
\end{array}\right) \\
& \mathrm{Q}(\mathrm{s})=\mathrm{G}(\mathrm{s}) \cdot \mathrm{D}(\mathrm{s})=\left(\begin{array}{cc}
\mathrm{g}_{11}(\mathrm{~s})-\frac{\mathrm{g}_{21}(\mathrm{~s}) \cdot \mathrm{g}_{12}(\mathrm{~s})}{\mathrm{g}_{22}(\mathrm{~s})} & 0 \\
0 & \mathrm{~g}_{22}(\mathrm{~s})-\frac{\mathrm{g}_{21}(\mathrm{~s}) \cdot \mathrm{g}_{12}(\mathrm{~s})}{\mathrm{g}_{11}(\mathrm{~s})}
\end{array}\right) \\
& \mathrm{D}(\mathrm{s})=\mathrm{G}(\mathrm{s})^{-1} \cdot\left(\operatorname{diag}\left(\mathrm{G}(\mathrm{s})^{-1}\right)\right)^{-1}
\end{aligned}
$$

In this work, further research regarding simplified decoupling was performed focusing on stable processes with possibly RHP zeros and time delays. Furthermore, its formulation was developed and generalized to $n \times n$ processes while the realizability conditions were presented. Various possible configurations were shown depending on the decoupler elements that are set to unity, where expressions (2) and (4) are only one of the choices. In addition, the formulation of a purely centralized control is achieved as a variation of simplified decoupling and its corresponding decentralized controller. Finally, a centralized PID control is obtained by controller reduction.

The paper is structured as follows. Section 2 presents the general formulation of simplified decoupling for $\mathrm{n} \times \mathrm{n}$ processes and the different possible configurations. Then, the realizability conditions are stated, followed by the derivation of the variation of centralized control by simplified decoupling. Some expressions for the $2 \times 2$ and $3 \times 3$ processes are shown. Section 3 describes some design and practical considerations related to the proposed methodologies, such as the decoupler approximation method, the reduction to multivariable PID control and the anti-windup implementation schemes. In Section 4, the performance of the proposed decoupling methodologies is tested and compared with other methods using several simulation examples and a real quadruple tank process. Finally, conclusions are given in Section 5.

\section{The methodology}

\subsection{General simplified decoupling}

Given a multivariable process $\mathrm{G}(\mathrm{s})$ and following the decoupling control system depicted in Figure 1, it is possible to obtain a decoupler network $\mathrm{D}(\mathrm{s})$ from (1) after specifying a diagonal apparent process $\mathrm{Q}(\mathrm{s})$. It is assumed that the process $\mathrm{G}(\mathrm{s})$ may have RHP zeros and multiple time delays, but it does not have unstable poles in the left half plane. Hereafter, Laplace variable s is omitted. The expression of the entire decoupler matrix $\mathrm{D}(\mathrm{s})$ is obtained as follows: 


$$
\mathrm{D}=\frac{\operatorname{adjG}}{|\mathrm{G}|} \cdot \mathrm{Q}=\left(\begin{array}{cccc}
\operatorname{adjG}_{11} \cdot \mathrm{q}_{1} & \operatorname{adjG}_{12} \cdot \mathrm{q}_{2} & \cdots & \operatorname{adjG}_{1 \mathrm{n}} \cdot \mathrm{q}_{\mathrm{n}} \\
\operatorname{adjG}_{21} \cdot \mathrm{q}_{1} & \operatorname{adjG}_{22} \cdot \mathrm{q}_{2} & \cdots & \operatorname{adjG}_{2 \mathrm{n}} \cdot \mathrm{q}_{\mathrm{n}} \\
\vdots & \vdots & \ddots & \vdots \\
\operatorname{adjG}_{\mathrm{n} 1} \cdot \mathrm{q}_{1} & \operatorname{adjG}_{\mathrm{n} 2} \cdot \mathrm{q}_{2} & \cdots & \operatorname{adjG}_{\mathrm{n}} \cdot \mathrm{q}_{\mathrm{n}}
\end{array}\right) /|\mathrm{G}|
$$

where $|\mathrm{G}(\mathrm{s})|$ is the determinant of $\mathrm{G}(\mathrm{s})$, adjG(s) is the adjugate matrix of $\mathrm{G}(\mathrm{s})$, that is, the transpose of the cofactor matrix of $\mathrm{G}(\mathrm{s})$, and $\operatorname{adjG}_{\mathrm{ij}}(\mathrm{s})$ is the $\operatorname{adjG}(\mathrm{i}, \mathrm{j})$ element, that is equivalent to the cofactor corresponding to $g_{\mathrm{ji}}(\mathrm{s})$. To force the diagonal elements of $\mathrm{D}(\mathrm{s})$ in (5) to be unity, it is necessary to select the apparent process given by (6). This apparent process is the inverse of the diagonal elements of adjG(s) multiplied by $|\mathrm{G}(\mathrm{s})|$. The decoupler in (7), which is the same decoupler obtained from (4), is then obtained.

$$
\begin{aligned}
& \mathrm{Q}(\mathrm{s})=\left(\begin{array}{cccc}
\frac{|\mathrm{G}|}{\operatorname{adjG}_{11}} & 0 & \cdots & 0 \\
0 & \frac{|\mathrm{G}|}{\operatorname{adjG}_{22}} & \cdots & 0 \\
\vdots & \vdots & \ddots & \vdots \\
0 & 0 & \cdots & \frac{|\mathrm{G}|}{\operatorname{adjG}_{\mathrm{nn}}}
\end{array}\right) \\
& \mathrm{D}(\mathrm{s})=\left(\begin{array}{cccc}
1 & \frac{\operatorname{adjG}_{12}}{\operatorname{adjG}_{22}} & \cdots & \frac{\operatorname{adjG}_{1 \mathrm{n}}}{\operatorname{adjG}_{\mathrm{nn}}} \\
\frac{\operatorname{adjG}_{21}}{\operatorname{adjG}_{11}} & 1 & \cdots & \frac{\operatorname{adjG}_{2 n}}{\operatorname{adjG}_{\mathrm{nn}}} \\
\vdots & \vdots & \ddots & \vdots \\
\frac{\operatorname{adjG} G_{\mathrm{n} 1}}{\operatorname{adjG} G_{11}} & \frac{\operatorname{adjG} G_{\mathrm{n}}}{\operatorname{adjG} G_{22}} & \cdots & 1
\end{array}\right)
\end{aligned}
$$

Nevertheless, this is only one possible configuration. In $n \times n$ processes, one decoupler element can be selected for each column to be set to unity because the decoupler elements of the same column are multiplied by the same apparent process $\mathrm{q}_{j}(\mathrm{~s})$ according to (5). Therefore, in $n \times n$ processes, there are $n^{n}$ possible choices of $D(s)$. To name these $\mathrm{n}^{\mathrm{n}}$ possibilities, the authors propose a notation in which the indicated number corresponds to the row with the selected element. For instance, in a $3 \times 3$ process, configuration 1-2-3 means that elements $\mathrm{D}(1,1), \mathrm{D}(2,2)$ and $\mathrm{D}(3,3)$ are chosen to be set to unity; as another example, configuration 3-1-1 means that elements $\mathrm{D}(3,1)$, $\mathrm{D}(1,2)$ and $\mathrm{D}(1,3)$ are selected.

Each configuration has a different set of decoupler elements, which is interesting because some choices can result in non-realizable decoupler elements. Thus, the configuration can be selected depending on the realizability. However, additional criteria can be proposed because each configuration is also related to a specific apparent process $\mathrm{Q}(\mathrm{s})$. For instance, in this work, the configuration is selected depending on the performance limitations of the corresponding apparent processes $\mathrm{q}_{\mathrm{i}}(\mathrm{s})$, checking different aspects like undershoot $(\%)$, overshoot $(\%)$ and settling time. There are $\mathrm{n}^{\mathrm{n}}$ different $Q(\mathrm{~s})$ as result of combinations of $\mathrm{n}$ elements (one chosen by column among $\mathrm{n}$ options in each column). For the $k$ column, there are only n possible $\mathrm{q}_{\mathrm{k}}(\mathrm{s})$; therefore, the 
total number of different $\mathrm{q}_{\mathrm{i}}(\mathrm{s})$ is $\mathrm{n} \times \mathrm{n}$. In a $3 \times 3$ process, there will be 9 different $\mathrm{q}_{\mathrm{i}}(\mathrm{s})$ to be checked, and there will be 27 different sets according to the possible combinations.

From (5), it is possible to obtain the general expressions of the simplified decoupling for $\mathrm{n} \times \mathrm{n}$ processes. If the configuration $\left\{\mathrm{p}_{1}-\mathrm{p}_{2}-\ldots-\mathrm{p}_{\mathrm{j}}-\ldots-\mathrm{p}_{\mathrm{n}-1}-\mathrm{p}_{\mathrm{n}}\right\}$ is chosen, the decoupler elements and apparent processes are given by (8) and (9), respectively.

$$
\begin{aligned}
& \mathrm{d}_{\mathrm{ij}}=\frac{\operatorname{adjG}_{\mathrm{ij}}}{\operatorname{adjG}_{\mathrm{kj}}} \quad \forall i, j ; k=p_{j} \\
& \mathrm{q}_{\mathrm{j}}=\frac{|\mathrm{G}|}{\operatorname{adjG}_{\mathrm{kj}}} \quad \forall j ; k=p_{j}
\end{aligned}
$$

After determining the decoupler network and the apparent processes, the parameters of the decentralized control $\mathrm{C}(\mathrm{s})$ can be tuned independently for the corresponding $\mathrm{q}_{\mathrm{j}}(\mathrm{s})$. Therefore, the existing SISO PID tuning methods [25-27] can be applied directly to guarantee the stability and performance of each loop. However, if the decoupled processes are very complex, it can be necessary to reduce the apparent processes or to use high-order controllers.

As a result, the proposed general simplified decoupling control is performed in three steps:

1- Select a configuration: that is, select the $n$ elements of $\mathrm{D}(\mathrm{s})$ to be set to unity, one for each column but not necessarily the diagonal ones.

2- Compose the decoupler elements of $\mathrm{D}(\mathrm{s})$ using (8).

3 - Design the $\mathrm{n}$ controllers of the diagonal control $\mathrm{C}(\mathrm{s})$ for the corresponding decoupled processes (9) using SISO design methods.

The decoupler is independent of the specifications, in such a way that different designs can be tested with the same $\mathrm{D}(\mathrm{s})$ matrix and redesigning the $\mathrm{n}$ controllers of $\mathrm{C}(\mathrm{s})$. This aspect is an advantage of this approach. In addition, the decoupler $\mathrm{D}(\mathrm{s})$ has $\mathrm{n}$ elements equal to one and this fact simplify its practical implementation.

\subsection{Decoupler realizability}

The realizability requirement for the decoupler is that all of its elements must be proper, causal and stable. For processes with time delays, non-minimum-phase zeros or different relative degrees, direct calculation of the decoupler can lead to elements with prediction, RHP poles or negative relative degrees. According to (8), the expression of a decoupler element is the division of two adjugate elements of the same column; therefore, there are three aspects to take into account and inspect in each column of $\operatorname{adjG(s):~time~delays,~relative~degrees~and~RHP~zeros.~Moreover,~one~element~in~each~}$ column of $\mathrm{D}(\mathrm{s})$ will be equal to one (as intended from simplified decoupling).

For a given configuration $\left\{\mathrm{p}_{1}-\mathrm{p}_{2}-\ldots-\mathrm{p}_{\mathrm{j}}-\ldots-\mathrm{p}_{\mathrm{n}-1}-\mathrm{p}_{\mathrm{n}}\right\}$, the following three conditions must be fulfilled for each column $j$ for the configuration to be realizable initially:

$$
\begin{aligned}
& \theta_{k j} \leq \theta_{i j} \quad \forall i ; k=p_{j} \\
& r_{k j} \leq r_{i j} \quad \forall i ; k=p_{j}
\end{aligned}
$$


$\eta_{k j} \leq \eta_{i j} \quad \forall i ; k=p_{j}$

where $\theta_{i j}$ is the time delay of adjG $\mathrm{ij}_{\mathrm{ij}}, r_{i j}$ is its relative degree and $\eta_{i j}$ its RHP zero multiplicity. Expression (12) must be satisfied for the different RHP zeros of the same column.

When non-realizability is originated for each column by only one of these three aspects, there will be another realizable configuration with n unitary elements. However, if nonrealizability in a column comes from several factors, it is possible that no configuration is initially realizable. Although configurations without extra dynamics can be preferred, every configuration may be forced to become realizable by multiplying each problematic column $j$ of $\mathrm{D}(\mathrm{s})$ by a minimum extra dynamics $\mathrm{n}_{\mathrm{j}}(\mathrm{s})$. It is equivalent to a new decoupler matrix $\mathrm{D}_{\mathrm{N}}(\mathrm{s})=\mathrm{D}(\mathrm{s}) \cdot \mathrm{N}(\mathrm{s})$, where $\mathrm{N}(\mathrm{s})$ is a diagonal matrix with the necessary extra dynamics. The only configurations that cannot become realizable are those that need to be divided by a zero adjugate element.

If there are no realizability problems in column $j$, the $\mathrm{N}(\mathrm{j}, \mathrm{j})$ element is equal to unity. If the non-realizability comes from an element with a non-causal time delay, an additional time delay $\theta_{n j}$ is inserted in the corresponding diagonal element of $\mathrm{N}(\mathrm{s})$ to obtain realizability. If the non-realizability comes from $\mathrm{N}_{\mathrm{z}}$ RHP zeros, which have become unstable poles, the following element with $\eta x_{n j}$ being corresponding multiplicity of the zero $\mathrm{z}_{\mathrm{x}}$ would be used in $\mathrm{N}(\mathrm{s})$ :

$\prod_{x=1}^{N z}\left(\frac{-s+z_{x}}{s+z_{x}^{*}}\right)^{\eta x_{n j}}$

where $\mathrm{z}_{\mathrm{x}} *$ is the complex conjugate of $\mathrm{z}_{\mathrm{x}}$. If it comes from a properness problem, a simple stable and fast pole with the adequate multiplicity $r_{n j}$ can be inserted as follows:

$\frac{1}{(\lambda s+1)^{r_{i j}}}$

To achieve realizability for a given configuration, the minimum extra dynamics that are necessary in each column $j$ is given by the following expressions:

$\theta_{\mathrm{nj}}=\max \left(\theta_{\mathrm{kj}}-\theta_{\mathrm{ij}}\right) \quad \forall \mathrm{i} ; \mathrm{k}=\mathrm{p}_{\mathrm{j}}$

$\mathrm{r}_{\mathrm{nj}}=\max \left(\mathrm{r}_{\mathrm{kj}}-\mathrm{r}_{\mathrm{ij}}\right) \quad \forall \mathrm{i} ; \mathrm{k}=\mathrm{p}_{\mathrm{j}}$

$\eta_{\mathrm{nj}}=\max \left(\eta_{\mathrm{kj}}-\eta_{\mathrm{ijj}}\right) \quad \forall \mathrm{i} ; \mathrm{k}=\mathrm{p}_{\mathrm{j}}$

When extra dynamics is inserted in a column to obtain realizability, the general expression of the decoupler elements is given by (16). All elements of the same column $j$ are multiplied by $n_{j}(s)$, and the previous unitary element is now equal to $n_{j}(s)$.

Additionally, the elements of the decoupled process $\mathrm{Q}(\mathrm{s})$ are all affected in the same way as given by (17).

$\mathrm{d}_{\mathrm{nij}}(\mathrm{s})=\frac{\operatorname{adjG}_{\mathrm{ij}}}{\operatorname{adjG}_{\mathrm{kj}}} \cdot \mathrm{n}_{\mathrm{j}} \quad \forall i, j ; k=p_{j}$ 
$\mathrm{q}_{\mathrm{nj}}(\mathrm{s})=\frac{|\mathrm{G}|}{\operatorname{adjG}_{\mathrm{kj}}} \cdot \mathrm{n}_{\mathrm{j}} \quad \forall j ; k=p_{j}$

After obtaining the necessary extra dynamics for each configuration, the following method is proposed to determine the most proper configurations and reduce alternatives (it is repeated by each column):

1. Calculate the $n$ different possible apparent processes $q_{n j}(s)$ for the column $j$.

2. In general, RHP zeros involve performance limitations in the bandwidth of the closed loop response and inverse response, so configurations that need extra dynamics like (13) are initially discarded, because according to (17) it will be included in the corresponding $\mathrm{q}_{\mathrm{nj}}(\mathrm{s})$.

3. Determine undershoot, overshoot and settling time of the $n$ different $\mathrm{q}_{\mathrm{nj}}(\mathrm{s})$ of the column $\mathrm{j}$ under study. The preferred choices are those apparent processes with smaller undershoot and overshoot in the response and smaller settling time, in order to achieve a faster and good closed loop response using PID controllers. Therefore, the apparent processes with undershoot or overshoot over $30 \%$ are discarded. If there are several $\mathrm{q}_{\mathrm{nj}}(\mathrm{s})$ with similar undershoot and overshoot, that with smaller settling time is selected. If there are several options with similar settling time among this last set, the apparent process with less extra dynamics is chosen.

\subsection{Centralized control by simplified decoupling}

The previous general simplified decoupling control system, depicted in Figure 1, consists of a decoupler $\mathrm{D}(\mathrm{s})$ with a unitary element for each column, combined with a diagonal controller $\mathrm{C}(\mathrm{s})$. This control strategy is equivalent to a multivariable controller $\mathrm{K}(\mathrm{s})$ using the pure centralized control scheme shown in Figure 2. From this scheme and from (16), the matrix and element expressions of $\mathrm{K}(\mathrm{s})$ can be expressed as (18) and (19).

$\mathrm{K}(\mathrm{s})=\mathrm{D}(\mathrm{s}) \cdot \mathrm{C}(\mathrm{s})$

$\mathrm{k}_{\mathrm{ij}}=\mathrm{c}_{\mathrm{j}} \cdot \mathrm{d}_{\mathrm{ij}}=\mathrm{c}_{\mathrm{j}} \cdot \frac{\operatorname{adjG}_{\mathrm{ij}}}{\operatorname{adjG}_{\mathrm{kj}}} \cdot \mathrm{n}_{\mathrm{j}} \quad \forall i, j ; k=p_{j}$

The proposed variation approaches the centralized design for $n \times n$ processes by $n$ SISO designs and n.(n-1) transfer function calculations. In particular, this variation includes the decoupling approach proposed in [19] when the $n$ elements equal to one in $\mathrm{D}(\mathrm{s})$ are the diagonal ones.

The $n$ controllers $c_{j}$ can have any structure. In this work, however, the PID structure is proposed in such a way that well-known PID tuning rules [25-27] can be used. In addition, a PID reduction is carried out for each controller element after obtaining the other $n \cdot(n-1)$ elements of $K(s)$. As a result, a centralized PID control $K^{\mathrm{PID}}(\mathrm{s})$ is obtained. This PID reduction process is explained later in Section 3.

2.4. Expressions of simplified decoupling for $2 \times 2$ and $3 \times 3$ processes 
In this section, the different expressions of the proposed method for $2 \times 2$ processes are presented using the general equations (8), (9) and (19). Table 1 summarizes the four possible configurations, and shows the different decoupler networks $\mathrm{D}(\mathrm{s})$, the centralized controllers $\mathrm{K}(\mathrm{s})$ and the apparent processes $\mathrm{Q}(\mathrm{s})$. In $3 \times 3$ processes, there are $27\left(3^{3}\right)$ configurations according to the three elements of $\mathrm{D}(\mathrm{s})$ chosen to be set to unity. Table 2 shows three of these configurations, in which $|\mathrm{G}(\mathrm{s})|$ and $\operatorname{adj} \mathrm{G}(\mathrm{s})$ are given by (20) and (21), respectively.

\section{INSERT HERE TABLE 1}

\section{INSERT HERE TABLE 2}

$$
\begin{gathered}
|G|=g_{11} \cdot g_{22} \cdot g_{33}+g_{12} \cdot g_{23} \cdot g_{31}+g_{13} \cdot g_{21} \cdot g_{32} \\
-g_{13} \cdot g_{22} \cdot g_{31}-g_{12} \cdot g_{21} \cdot g_{33}-g_{11} \cdot g_{23} \cdot g_{32} \\
\operatorname{adjG}=\left(\begin{array}{lll}
g_{22} \cdot g_{33}-g_{23} \cdot g_{32} & g_{13} \cdot g_{32}-g_{12} \cdot g_{33} & g_{12} \cdot g_{23}-g_{13} \cdot g_{22} \\
g_{23} \cdot g_{31}-g_{21} \cdot g_{33} & g_{11} \cdot g_{33}-g_{13} \cdot g_{31} & g_{13} \cdot g_{21}-g_{11} \cdot g_{23} \\
g_{21} \cdot g_{32}-g_{22} \cdot g_{31} & g_{12} \cdot g_{31}-g_{11} \cdot g_{32} & g_{11} \cdot g_{22}-g_{12} \cdot g_{21}
\end{array}\right)
\end{gathered}
$$

From Table 2 and expressions (20) and (21), it can be concluded that the decoupler elements or apparent processes in $3 \times 3$ systems are much more complex than those obtained in $2 \times 2$ processes. Consequently, a reduction may be advisable for the design and implementation of the control system.

\subsection{Stability}

The first condition for stability that the final controller $\mathrm{K}(\mathrm{s})$ must fulfill is that all of its elements must not have RHP poles. Once the stability of the controller is assured, internal stability of the closed loop system can be verified if and only if all elements in matrix (22) have all their poles in the left-half plane with no RHP pole-zero cancellation in $\mathrm{G}(\mathrm{s}) \cdot \mathrm{K}(\mathrm{s})[24]$.

$$
\left[\begin{array}{cc}
(\mathrm{I}+\mathrm{K}(\mathrm{s}) \cdot \mathrm{G}(\mathrm{s}))^{-1} & -\mathrm{K}(\mathrm{s}) \cdot \mathrm{S}(\mathrm{s}) \\
\mathrm{S}(\mathrm{s}) \mathrm{G}(\mathrm{s}) & \mathrm{S}(\mathrm{s})
\end{array}\right\rfloor
$$

In this case, $S(s)$ is the sensitivity transfer function matrix written as $[\mathrm{I}+\mathrm{G}(\mathrm{s}) \cdot \mathrm{K}(\mathrm{s})]^{-1}$. $\mathrm{K}(\mathrm{s})$ can represent the pure centralized control or the decentralized controller in series with the decoupler according to (18).

As mentioned previously, the elements of $\mathrm{D}(\mathrm{s})$ and $\mathrm{Q}(\mathrm{s})$ obtained using simplified decoupling are more complex than those obtained using inverted decoupling. Processes with time delays generally need some approximation to be implemented, which is an important disadvantage over inverted decoupling. Therefore, inverted decoupling is preferable when applicable. However, it cannot be applied to processes with RHP zeros in the determinant of the G(s) because these RHP zeros should appear in the apparent process. Fortunately, simplified decoupling can be applied in these cases because $|\mathrm{G}(\mathrm{s})|$ 
and the consequent RHP zeros are directly included in the apparent decoupled process $\mathrm{Q}$ (s) according to (9) or (17).

\section{Design and practical considerations}

\subsection{Approximation of $|\mathrm{G}(\mathrm{s})|$ and $\operatorname{adj} \mathrm{G}(\mathrm{s})$}

To carry out the proposed methodologies in multivariable time delay systems, it is usually necessary to approximate the expressions of the determinant of the process $|\mathrm{G}(\mathrm{s})|$ and its adjugate matrix adjG(s). Although the process dynamics are simple, direct calculations using equations like (20) or (21) can give rise to non-rational expressions that are very complicated and difficult to implement (as shown in (23)):

$$
M(s)=\frac{\left(-0.0089 \cdot(5.6 s+1) \cdot e^{-2 s}+0.0051 \cdot(10 s+1)\right)}{(5.6 s+1) \cdot(8 s+1) \cdot(10 s+1)} e^{-3 s}
$$

Therefore, before continuing with the design methodology, it is more preferable to approximate such elements by rational transfer functions plus a possible time delay. Because it is easy to obtain the frequency response of $|\mathrm{G}(\mathrm{jw})|$ and $\operatorname{adjG(jw)~from~the~}$ process frequency response $\mathrm{G}(\mathrm{jw})$, a parametric approximation in the frequency domain is proposed. Several techniques can be used for this purpose. Some are based on least squares estimators [28]; others, such as the prediction error method (PEM), are based on an iterative estimation method that minimizes the prediction errors to obtain maximum likelihood estimates.

In this work, a simple linear least square approximation is proposed in the frequency range of interest as an example. The lowest frequency is chosen two decades below the smallest absolute value of the real part of the different poles and zeros of $G(s)$; the highest frequency is chosen two decades above the greatest one. The procedure is shown in the following steps.

\subsubsection{Previous information}

To facilitate the approximation, the following previous information about the function is obtained from the Bode plots of its frequency response and from $\mathrm{G}(\mathrm{s})$ :

a) External time delay. A general expression for the non-zero element of $\operatorname{adj}_{\mathrm{ij}}(\mathrm{s})$ or $|\mathrm{G}(\mathrm{s})|$ is [6]:

$$
\phi(s)=\sum_{k=1}^{M} \phi_{k}(s) \cdot e^{-\alpha_{k} s} \quad \alpha_{k} \geq 0
$$

where $\phi_{\mathrm{k}}(\mathrm{s})$ is a non-zero scalar rational transfer function that is obtained as a product of some process transfer functions $g_{i j}(s)$; the corresponding time delay $\alpha_{k}$ is the sum of the time delays of these transfer functions $\mathrm{g}_{\mathrm{ij}}(\mathrm{s})$. Therefore, the time delay for $\phi(\mathrm{s})$ is defined as follows

$$
\tau(\phi(s))=\min _{k=1, \ldots, M}\left(\alpha_{k}\right)
$$


From the time delay matrix of $\mathrm{G}(\mathrm{s})$, the corresponding time delays of $|\mathrm{G}(\mathrm{s})|$ and $\operatorname{adjG}(\mathrm{s})$ can then be derived. For instance, assuming non-zero elements, the time delay of $\operatorname{adjG}_{11}(\mathrm{~s})$ in (21) would be

$$
\tau\left(\operatorname{adj} \mathrm{G}_{11}\right)=\min \left(\alpha_{1}, \alpha_{2}\right)=\min \left(\tau\left(\mathrm{g}_{22}\right)+\tau\left(\mathrm{g}_{33}\right), \tau\left(\mathrm{g}_{23}\right)+\tau\left(\mathrm{g}_{32}\right)\right)
$$

b) Relative degree. This value can be calculated from the high frequency roll-off of the module Bode plot. If the relative degree is $r d$, the rate of roll-off will be $-20 \cdot r d$ $\mathrm{dB} /$ decade. Even though this rate is not exactly constant because of the non-rational nature of the function to be approximated, a general trend can be estimated.

c) Original poles. $|\mathrm{G}(\mathrm{s})|$ and $\operatorname{adjG}(\mathrm{s})$ are the result of the sums and products of different elements of $\mathrm{G}(\mathrm{s})$, respectively as shown in (20) and (21) for $3 \times 3$ systems. Thus, assuming that there are no pole-zero cancellations after these operations, the poles of $|\mathrm{G}(\mathrm{s})|$ and $\operatorname{adjG}_{\mathrm{ij}}(\mathrm{s})$ can be calculated. The integrators (poles in $\mathrm{s}=0$ ) will be removed from the frequency response before the approximation.

d) Number of RHP zeros. After removing the previous external time delay and integrators from the frequency response, the number of RHP zeros can be estimated from the phase shift in the phase Bode plot if the phase at high frequencies tends or oscillates around a constant value. Assuming that the relative degree $r d$, the low frequency phase $\varphi_{0}$ and high frequency phase $\varphi_{\text {end }}$ are known, the number of RHP zeros $\mathrm{N}_{\mathrm{Z}}$ in this case can be obtained from (27):

$$
N_{z}=\frac{\varphi_{\text {end }}-\varphi_{o}+90^{\circ} \cdot r d}{-180^{\circ}}
$$

As an example, Figure 3 shows the Bode plots of the irrational transfer function in (23) after removing the external time delay of three units and the stationary gain equal to 0.0038 . The corresponding approximation is also shown. As previously commented, the rate of roll-off at high frequencies is not entirely constant; however, a trend of approximately $-40 \mathrm{~dB} /$ decade can be observed, and a relative degree equal to 2 is obtained as previously explained. Similarly, the phase at high frequencies oscillates; in this case, it oscillates around a constant phase of $-360^{\circ}$. Therefore, expression (27) indicates that the approximation model should have a RHP zero.

\section{INSERT HERE FIGURE 3}

Nevertheless, the high frequency phase at several instances does not tend to a constant value and the previous estimation was not valid because of the irrationality of some functions that were to be approximated. Therefore, $\mathrm{N}_{\mathrm{z}}$ is assumed to be zero and the existence of RHP zeros will depend on the approximation.

Before carrying out the least square approximation, the time delay and possible integrators are removed from the frequency response data in order to simplify the approximation. Additionally, this new response is divided by its stationary gain; this results in the new frequency response $\mathrm{H}(\mathrm{jw})$ to be approximated. Then, using the previous information about relative degree, number of RHP zeros, original poles and 
integrators, the simplest parametric model and the more complex parametric model for the approximation of $\mathrm{H}(\mathrm{jw})$ are calculated.

The approximation method is applied to the simplest model. If the method does not produce a good fit, the orders are progressively increased until a good fit is obtained or the most complex model is reached. In the latter case or when unstable models are obtained, the tolerance for a good fit is relaxed, and the process is restarted. After achieving a good estimated model $\mathrm{N}(\mathrm{s}) / \mathrm{D}(\mathrm{s})$, the removed time delay, stationary gain and possible integrators are added back in.

\subsubsection{Approximation method}

Assuming that the frequency response $\mathrm{H}(\mathrm{jw})$ is intended to be approximated by a model $\mathrm{N}(\mathrm{s}) / \mathrm{D}(\mathrm{s})$ with orders $\mathrm{p}$ and $\mathrm{q}$ in the numerator and denominator respectively, the corresponding rational transfer function to be estimated with unitary stationary gain, is given by

$$
\frac{\mathrm{N}(\mathrm{s})}{\mathrm{D}(\mathrm{s})}=\frac{\alpha_{p} s^{p}+\ldots+\alpha_{2} s^{2}+\alpha_{1} s+1}{\beta_{q} s^{q}+\ldots+\beta_{2} s^{2}+\beta_{1} s+1}
$$

The proposed weighted linear least square method tries to minimize the following cost function $\mathbf{J}$ in $(29)$, where $\mathrm{W}(\mathrm{jw}, \beta)$ given in $(30)$ is a weighting function to minimize the relative error criterion [28].

$$
\begin{aligned}
& \min \mathrm{J}=\sum_{\mathrm{k}=1}^{\mathrm{M}} \mathrm{W}\left(\mathrm{jw_{ \textrm {k } }}, \beta\right) \cdot\left|\mathrm{H}\left(\mathrm{jw_{ \textrm {k } }}\right) \cdot \mathrm{D}\left(\mathrm{jw_{ \textrm {k } }}, \beta\right)-\mathrm{N}\left(\mathrm{jw_{ \textrm {k } }}, \alpha\right)\right|^{2} \\
& \mathrm{~W}\left(\mathrm{jw_{ \textrm {k } }}, \beta^{\mathrm{i}}\right)=\frac{1}{\left|\mathrm{H}\left(\mathrm{jw}_{\mathrm{k}}\right) \cdot \mathrm{D}\left(j \mathrm{w}_{\mathrm{k}}, \beta^{\mathrm{i}-1}\right)\right|}
\end{aligned}
$$

The measurement used to determine whether the estimated model is "good" is the mean squared error (MSE). If the MSE is under the pre-specified tolerance, the approximation model is acceptable. Initially, the tolerance is $10^{-5}$.

For instance, the minimum orders of denominator and numerator model in the case of expression (23) according to its information obtained previously should be three and one, respectively; in addition, the two values coincide with the maximum model orders. After removing the time delay and stationary gain and applying the proposed method, the approximated model with Bode plots depicted in Figure 3 is obtained. It shows a good fit in comparison with the corresponding original frequency response with a MSE of $8.39 \cdot 10^{-5}$. Then, the final model in (31) is obtained after adding back the time delay and the original stationary gain.

$$
M_{a p}(\mathrm{~s})=\frac{(-0.0038)(-7.54 \mathrm{~s}+1)}{\left(143.4 \mathrm{~s}^{3}+131.1 \mathrm{~s}^{2}+20.93 \mathrm{~s}+1\right)} \mathrm{e}^{-3 \mathrm{~s}}
$$

$$
\text { 3.2. Model reduction of } \mathrm{D}(\mathrm{s}) \text { and } \mathrm{Q}(\mathrm{s})
$$


After approximation, $|\mathrm{G}(\mathrm{s})|$ and all of elements of adjG(s) are expressed as a rational transfer function plus time delay. Therefore, the realizability of each configuration $\left\{\mathrm{p}_{1^{-}}\right.$ $\left.\mathrm{p}_{2}-\ldots-\mathrm{p}_{\mathrm{j}}-\ldots-\mathrm{p}_{\mathrm{n}-1}-\mathrm{p}_{\mathrm{n}}\right\}$ can be analyzed, determining the necessary extra dynamics with (15). Then, the elements of $\mathrm{D}(\mathrm{s})$ and $\mathrm{Q}(\mathrm{s})$ can be obtained using (16) and (17), respectively. However, in some cases, the order of these elements can be too high and a model reduction may be necessary for simpler implementation. In this work, we proposed a known model reduction technique based on balanced residualization. It is only applied to the rational part of the transfer function, which preserves the same time delay.

First, a minimal realization (A, B, C, D) of the transfer function to be reduced is calculated. Then, this is balanced by a state similarity transformation, resulting in a balanced realization. Next, the ordered Hankel singular values $\sigma_{i}$ of this balanced realization are computed. In a balanced realization, the value of each $\sigma_{i}$ is associated with a state $\mathrm{x}_{\mathrm{i}}$ of the balanced system. The size of the Hankel singular value $\sigma_{\mathrm{i}}$ measures the contribution of each state $x_{i}$ to the input-output behavior. Thus, if $\sigma_{1} \gg \sigma_{2}$, the state $\mathrm{x}_{1}$ affects the input-output behavior much more than $\mathrm{x}_{2}$ (or any other state) because of the ordering of $\sigma_{\mathrm{i}}$ [24]. Then, these small Hankel singular values signal states can be safely removed to simplify the model.

In this work, the state $x_{i}$ and the following ones can be removed if $\sigma_{1} \gg \varepsilon \cdot \sigma_{i}$, where $\varepsilon$ is a given tolerance factor (for example 10). Once the number of states to be discarded is determined, the simplification is performed by a balanced residualization (setting the derivatives of all these states to zero). This method is called a singular perturbation approximation of a balanced system. The method has been selected because it preserves the steady-state gain of the system, and it has a better performance than other techniques at low and medium frequencies [24].

\subsection{Controller reduction to multivariable PID}

As previously mentioned in subsection 2.3 , all of the controller elements of $\mathrm{K}(\mathrm{s})$ given by (19) must be approximated by PID controllers to achieve a centralized PID control. The PID structure used in this work is the parallel form of (32), where $K_{P}$ is the proportional constant, $\mathrm{K}_{\mathrm{I}}$ the integral constant, $\mathrm{K}_{\mathrm{D}}$ the derivative constant and $\mathrm{T}_{\mathrm{F}}$ is the derivative filter constant. Although the parameters have little physical interpretation in this form, it is the most flexible structure that allows independency between the different control actions.

$$
\mathrm{k}^{\mathrm{PID}}(\mathrm{s})=K_{P}+\frac{K_{I}}{s}+\frac{K_{D} s}{T_{F} s+1}
$$

The PID controller can be obtained using the approximation method described in subsection 3.1. However, the authors propose to remove the integrator of the controller element $\mathrm{k}_{\mathrm{ij}}(\mathrm{s})$ and apply the model reduction to the inverse of this result $\mathrm{m}(\mathrm{s})$ instead of reducing the controller element. The new stationary gain $\mathrm{k}_{0}$, as shown in (33), would be identified with the integral constant $\mathrm{K}_{\mathrm{I}}$.

$$
\mathrm{k}_{0}=\lim _{s \rightarrow 0}[\mathrm{k}(\mathrm{s}) \cdot \mathrm{s}]=\lim _{s \rightarrow 0}[\mathrm{~m}(\mathrm{~s})]
$$


Without the integrator and after dividing by $\mathrm{k}_{0}$, the frequency response of the inverse of $\mathrm{m}(\mathrm{s})$ should be approximated according to (34):

$$
\frac{\mathrm{k}_{0}}{\mathrm{~m}(\mathrm{~s})} \approx \frac{\mathrm{b}_{1} \mathrm{~s}+1}{\mathrm{a}_{2} \mathrm{~s}^{2}+\mathrm{a}_{1} \mathrm{~s}+1}=\frac{\mathrm{T}_{\mathrm{F}} \mathrm{s}+1}{\left(\frac{\mathrm{K}_{\mathrm{P}} \mathrm{T}_{\mathrm{F}}+\mathrm{K}_{\mathrm{D}}}{\mathrm{K}_{\mathrm{I}}}\right) \mathrm{s}^{2}+\left(\frac{\mathrm{K}_{\mathrm{P}}}{\mathrm{K}_{\mathrm{I}}}+\mathrm{T}_{\mathrm{F}}\right)+1}
$$

In this way, the PID gains after approximation can be identified as follows

$$
\begin{aligned}
& \mathrm{K}_{\mathrm{P}}=\left(\mathrm{a}_{1}-\mathrm{b}_{1}\right) \cdot \mathrm{k}_{0} \\
& \mathrm{~K}_{\mathrm{I}}=\mathrm{k}_{0} \\
& \mathrm{~K}_{\mathrm{D}}=\mathrm{a}_{2} \cdot \mathrm{k}_{0}-\mathrm{b}_{1} \cdot\left(\mathrm{a}_{1}-\mathrm{b}_{1}\right) \cdot \mathrm{k}_{0} \\
& \mathrm{~T}_{\mathrm{F}}=\mathrm{b}_{1}
\end{aligned}
$$

For PI approximation, $\mathrm{K}_{\mathrm{D}}$ and $\mathrm{T}_{\mathrm{F}}$ are removed; therefore, the coefficients $\mathrm{b}_{1}$ and $\mathrm{a}_{2}$ would be zero. Both PI and PID approximations are obtained, the one with the best fit is chosen.

There are multivariable processes that are too complex to be controlled by a multivariable PID control; the controllers would at least have difficulties fulfilling very restrictive specifications in decoupling and loop performances. In these cases, the specifications should be relaxed to make the response more sluggish; alternatively, higher order controllers should be used [6].

\subsection{Anti-windup implementation schemes}

From an implementation point of view, it is important to consider how to solve practical problems such as wind-up, which can cause the controller to perform poorly in the presence of control signal constraints. For SISO PID controllers, different anti-windup schemes are explained in [29], such as the back-calculation method. Nevertheless, it is more difficult to find wind-up solutions for the multivariable case. A possible antiwindup scheme for simplified decoupling is described in [30]. It can be used for the proposed simplified decoupling plus decentralized PID control $\mathrm{D}(\mathrm{s}) \cdot \mathrm{C}(\mathrm{s})$.

In a multivariable PID control system $\mathrm{K}^{\mathrm{PID}}(\mathrm{s})$ in which all of its elements have PID structures, each manipulated variable is composed by the sum of several PID actions. In this case, the wind-up problem becomes difficult to handle; in addition, the contribution of each PID controller to the corresponding process input is difficult to coordinate when saturation occurs. For a multivariable PID control system with two inputs and two outputs, the anti-windup scheme depicted in Figure 4 is proposed. Although no commercial solution uses this scheme, it can be implemented using function blocks of a distributed control system (DCS).

The key idea is to use only one integrator for each manipulated variable so that the back-calculation method can be easily implemented in order to avoid wind-up. To do so, the different integral actions associated with the same manipulated variable are collected. On the other hand, the proportional and derivative actions (PD) remain separated. 
For instance, the unsaturated control signal $\mathrm{u}_{1}$ would be calculated according to (36), where $e_{i}$ is the error signal. When the control signal is saturated while $u_{1}$ is different from $\mathrm{u}_{1 \_\mathrm{SAT}}$, the real process input $\mathrm{u}_{1 \_\mathrm{SAT}}$ works as tracking signal through the gain $\mathrm{K}_{\mathrm{R} 1}$. Then, the back-calculation method will make the integrator act in consequence to reduce this difference. Similar actions can be performed on the other control signal $u_{2}$.

\section{INSERT HERE FIGURE 4}

$$
\begin{aligned}
& u_{1}(\mathrm{~s})=\left(K_{P 11}+\frac{K_{I 11}}{s}+\frac{K_{D 11} s}{T_{F 11} s+1}\right) e_{1}(\mathrm{~s})+\left(K_{P 12}+\frac{K_{I 12}}{s}+\frac{K_{D 12} s}{T_{F 12} s+1}\right) e_{2}(\mathrm{~s})+\frac{K_{R 1}\left(u_{1 S A T}(\mathrm{~s})-u_{1}(\mathrm{~s})\right)}{s}= \\
& =\left(K_{P 11}+\frac{K_{D 11} s}{T_{F 11} s+1}\right) e_{1}(\mathrm{~s})+\left(K_{P 12}+\frac{K_{D 12} s}{T_{F 12} s+1}\right) e_{2}(\mathrm{~s})+\frac{\left(K_{I 11} e_{1}(\mathrm{~s})+K_{I 12} e_{2}(\mathrm{~s})\right)+K_{R 1}\left(u_{1 S A T}(\mathrm{~s})-u_{1}(\mathrm{~s})\right)}{s}=(36) \\
& =\mathrm{PD}_{11} e_{1}(\mathrm{~s})+\mathrm{PD}_{12} e_{2}(\mathrm{~s})+\frac{\left(K_{I 11} e_{1}(\mathrm{~s})+K_{I 12} e_{2}(\mathrm{~s})\right)+K_{R 1}\left(u_{1 S A T}(\mathrm{~s})-u_{1}(\mathrm{~s})\right)}{s}
\end{aligned}
$$

The gain constant $K_{R}$ can be tuned by trial and error; however, we propose to tune it according to (37) at the first attempt. Even though this anti-windup scheme is presented for TITO control systems, it can be extended to higher number of inputs and outputs.

$$
\mathrm{K}_{\mathrm{Ri}}=\beta \cdot \max \left(\left|\mathrm{K}_{\mathrm{Ijj}}\right|\right) \quad \forall \mathrm{j} ; \quad \beta \in[4,20]
$$

\section{Examples}

In this section, the proposed methodology is applied to three simulated processes with different dimensions. Additionally, the effectiveness of the methods is verified in a real quadruple tank plant. Inverted decoupling cannot be applied to any of these processes because of the existence of multivariable non-minimum zeros. Therefore, the use of the proposed methods is justified.

\subsection{Example 3×3: Depropanizer column}

The process is a depropanizer column to separate propane from the feed that comes from deethanizer column [6], and it is given by a $3 \times 3$ transfer function matrix in (38).

$$
\mathrm{G}_{\mathrm{D}}(\mathrm{s})=\left(\begin{array}{cccc}
\frac{-0.26978 e^{-27.5 s}}{97.5 s+1} & \frac{1.978 e^{-53.5 s}}{118.5 s+1} & \frac{0.07724 e^{-56 s}}{96 s+1} \\
\frac{0.4881 e^{-117 s}}{56 s+1} & \frac{-5.26 e^{-26.5 s}}{58.5 s+1} & \frac{0.19996 e^{-35 s}}{51 s+1} \\
\frac{0.6 e^{-16.5 s}}{40.5 s+1} & \frac{5.5 e^{-15.5 s}}{19.5 s+1} & \frac{-0.5 e^{-17 s}}{18 s+1}
\end{array}\right)
$$

Because of the time delays of (38), it is necessary to approximate $\left|G_{D}(s)\right|$ and the elements of the adjugate matrix adjG(s) into rational transfer functions plus time delay to apply the proposed methodologies. After this approximation, the extra dynamics $\mathrm{N}(\mathrm{s})$ needed to achieve realizability for the different configurations are obtained according to (15) and the nine possible apparent processes $\mathrm{q}_{\mathrm{i}}(\mathrm{s})$ are obtained with (17). The only configuration without extra dynamics is the configuration 3-3-3. Nevertheless, using the criteria proposed in section 2.2, configuration 1-2-3 with extra dynamics given by $\mathrm{n}_{11}(\mathrm{~s})$ 
$=\mathrm{e}^{-0.5 \mathrm{~s}}, \mathrm{n}_{22}(\mathrm{~s})=\mathrm{e}^{-1.5 \mathrm{~s}}$ and $\mathrm{n}_{33}(\mathrm{~s})=1$ should be selected because it is the configuration with smaller undershoots in its corresponding $\mathrm{q}_{\mathrm{i}}(\mathrm{s})$. The decoupler network $\mathrm{D}(\mathrm{s})$ and apparent processes $\mathrm{q}_{\mathrm{i}}(\mathrm{s})$ calculated with (16) and (17) resulted in (39) and (40), respectively.

$$
\mathrm{D}(\mathrm{s})=\left(\begin{array}{ccc}
e^{-0.5 s} & \frac{-0.8903 s^{2}+28.33 s+0.6488}{s^{2}+3.422 s+0.04063} e^{-27.5 s} & \frac{-0.2081 s^{2}+3.549 s+0.1759}{s^{2}+19.42 s+0.09951} e^{-28.5 s} \\
\frac{-0.0778 s^{2}-0.00479 s+0.00049}{s^{2}+0.09996 s+0.0002077} e^{-8.5 s} & e^{-1.5 s} & \frac{0.0338 s^{2}+0.00053 s+9.79 \cdot 10^{-6}}{s^{2}+0.01202 s+4.847 \cdot 10^{-5}} e^{-8.5 s} \\
\frac{0.4168 s^{2}+0.0578 s+0.0007013}{s^{2}+0.02302 s+0.0001837} & \frac{9.438 s^{2}+7.394 s+0.3465}{s^{2}+0.9045 s+0.01149} & 1
\end{array}\right)
$$

$$
\begin{aligned}
& \mathrm{q}_{1}(\mathrm{~s})=\frac{0.003581 s^{3}-0.001936 s^{2}-0.0001537 s+2.083 \cdot 10^{-6}}{s^{3}+0.03933 s^{2}+0.0007587 s+4.203 \cdot 10^{-6}} e^{-28 s} \\
& \mathrm{q}_{2}(\mathrm{~s})=\frac{-0.04627 s^{3}-0.04643 s^{2}-0.002306 s+3.384 \cdot 10^{-5}}{s^{3}+0.03638 s^{2}+0.0006908 s+3.951 \cdot 10^{-6}} e^{-28 s} \\
& \mathrm{q}_{3}(\mathrm{~s})=\frac{0.0105 s^{4}-0.01614 s^{3}+2.69 \cdot 10^{-5} s^{2}-1.538 \cdot 10^{-6} s+4.09 \cdot 10^{-8}}{s^{4}+0.03737 s^{3}+0.000784 s^{2}+7.277 \cdot 10^{-6} s+2.447 \cdot 10^{-8}} e^{-17 s}
\end{aligned}
$$

The parameters of the decentralized PID controller are tuned independently for the corresponding $\mathrm{q}_{\mathrm{i}}(\mathrm{s})$ according to [26]. A gain margin of 3 and a phase margin of $60^{\circ}$ are used as specifications in the three loops. The parameters of the resulting PID controllers are listed in Table 3. The decoupler $\mathrm{D}(\mathrm{s})$ plus the decentralized control $\mathrm{C}(\mathrm{s})$ is the proposed simplified decoupling control for $\mathrm{G}_{\mathrm{D}}(\mathrm{s})$.

The elements of the centralized control by simplified decoupling K(s) are obtained according to (19). The elements are then approximated in PID controller using the method described in subsection 3.3. The resulting PID parameters of $\mathrm{K}^{\mathrm{PID}}(\mathrm{s})$ are collected in Table 3 . This is the proposed multivariable PID control by simplified decoupling (MV-PID).

\section{INSERT HERE TABLE 3}

To verify the nominal control system performance, the closed loop system responses are shown in Figure 5. There are unit step changes at $\mathrm{t}=0 \mathrm{~s}$ in the first reference, at $\mathrm{t}=$ $2000 \mathrm{~s}$ in the second reference, and at $\mathrm{t}=4000 \mathrm{~s}$ in the third one; at $\mathrm{t}=6000 \mathrm{~s}$, there is a 0.1 step in all process inputs at the same time as input disturbance. The IAE of each loop is obtained as performance indices and collected in Table 3. For comparison, other control methodologies are also shown in the figure including the centralized non-PID control of Wang in [6] and a multiloop PID controller. The multiloop PID controller is tuned according to Lee's method [4] to achieve similar performance: a gain margin of 3 and a phase margin of $60^{\circ}$ in each loop. According to the relative gain array (RGA), the chosen pairing has been $\mathrm{y}_{1}-\mathrm{u}_{2}, \mathrm{y}_{2}-\mathrm{u}_{3}$ and $\mathrm{y}_{3}-\mathrm{u}_{1}$. The PID parameters are shown in Table 3 with the corresponding IAE indices.

\section{INSERT HERE FIGURE 5}

There is no practically difference between the two proposed methodologies. Both perform better than the multiloop PID control that has very important interactions in outputs $\mathrm{y}_{2}$ and $\mathrm{y}_{3}$. The response of the proposed methods is quite similar to that of Wang's controller; however, the proposed methods produce smaller IAE. In addition, 
the complexity of the proposed multivariable PID control is much simpler than that of Wang's control $\mathrm{K}_{\mathrm{w}}(\mathrm{s})$.

To evaluate the robustness of the proposed controllers, a $\mu$-analysis is performed in the presence of diagonal multiplicative input uncertainty. To achieve robust stability, the necessary and sufficient condition [24] is

$$
\mu_{\mathrm{RS}}=\mu\left[-\mathrm{W}_{\mathrm{I}}(\mathrm{s}) \mathrm{T}_{\mathrm{I}}(\mathrm{s})\right]<1 \quad \forall \omega
$$

where $\mu$ is the structured singular value (SSV) and $\mathrm{T}_{\mathrm{I}}(\mathrm{s}$ ) (equal to $\left.\mathrm{K}(\mathrm{s}) \cdot \mathrm{G}(\mathrm{s}) \cdot(\mathrm{I}+\mathrm{K}(\mathrm{s}) \cdot \mathrm{G}(\mathrm{s}))^{-1}\right)$ is the input complementary sensitivity function. $\mathrm{W}_{\mathrm{I}}(\mathrm{s})$ and $\mathrm{W}_{\mathrm{P}}(\mathrm{s})$ are the diagonal weights for uncertainty and performance, respectively. To evaluate whether the closed loop system will respect the desired performance even in the presence of diagonal multiplicative input uncertainty, the necessary and sufficient condition [24] is

$$
\mu_{\mathrm{RP}}=\mu\left\lfloor\begin{array}{cc}
-\mathrm{W}_{\mathrm{I}}(\mathrm{s}) \mathrm{T}_{\mathrm{I}}(\mathrm{s}) & -\mathrm{W}_{\mathrm{I}}(\mathrm{s}) \mathrm{K}(\mathrm{s}) \mathrm{S}(\mathrm{s}) \\
\mathrm{W}_{\mathrm{P}}(\mathrm{s}) \mathrm{S}(\mathrm{s}) \mathrm{G}(\mathrm{s}) & \mathrm{W}_{\mathrm{P}}(\mathrm{s}) \mathrm{S}(\mathrm{s})
\end{array}\right\rfloor<1 \quad \forall \omega
$$

In this example, the selected weights are

$$
\begin{aligned}
& W_{I}(\mathrm{~s})=w_{I}(\mathrm{~s})=\frac{(0.009 \mathrm{~s}+0.15)}{0.0045 s+1} \cdot I \\
& W_{P}(\mathrm{~s})=w_{P}(\mathrm{~s})=\frac{(\mathrm{s} / 2.75+0.00075)}{s} \cdot I
\end{aligned}
$$

The weight $w_{I}(\mathrm{~s})$ can be loosely interpreted as the process inputs increase by up to $200 \%$ uncertainty at high frequencies and by almost $15 \%$ uncertainty in the low frequency range. The performance weight $w_{P}(\mathrm{~s})$ specifies integral action and a maximum peak for $\bar{\sigma}(\mathrm{S})$ of $M_{S}=2.75$. Figure 6 shows the SSV for robust stability (RS) and robust performance (RP) for the different controllers under conditions (41) and (42). The RS is smaller than one for all frequencies, indicating that the systems will remain stable in spite of an uncertainty of $15 \%$ on each process input. The peak values are shown in Table 3. Although Wang's controller has the smallest value, the peak values of the proposed methods are very close to Wang's value. The RP analysis shows that both proposed methods satisfy the RP condition (42) in a similar way. For the other controllers, the performance will deteriorate at frequencies around $0.01 \mathrm{rad} / \mathrm{s}$, where the peaks appear. These values are also collected in Table 3. The multiloop PID controller has a good RS; however, it shows the worst robust performance that is due to the strong interactions in the second and third loops.

\section{INSERT HERE FIGURE 6}

\subsection{Example 4×4: Alatiqi distillation column}

In this example, three different configurations of simplified decoupling are designed and compared. The transfer function matrix $G_{A}(s)$ for the Alatiqi column system case 1 (A1 $4 \times 4)$ in [31] is given by (44). Because of the time delays of $G_{A}(s)$, it is once again necessary to approximate $\left|\mathrm{G}_{\mathrm{A}}(\mathrm{s})\right|$ and the elements of adjG(s) into rational transfer 
functions plus time delay. The 16 different apparent processes $\mathrm{q}_{\mathrm{i}}(\mathrm{s})$ are calculated according to (17) in order to analyze the possible configurations.

$$
\mathrm{G}_{\mathrm{A}}(\mathrm{s})=\left(\begin{array}{ccccc}
\frac{2.22 e^{-2.5 s}}{(36 \mathrm{~s}+1)(25 \mathrm{~s}+1)} & \frac{-2.94(7.9 \mathrm{~s}+1) e^{-0.05 s}}{(23.7 \mathrm{~s}+1)^{2}} & \frac{0.017 e^{-0.2 s}}{(31.6 \mathrm{~s}+1)(7 \mathrm{~s}+1)} & \frac{-0.64 e^{-20 s}}{(29 \mathrm{~s}+1)^{2}} \\
\frac{-2.33 e^{-5 s}}{(35 \mathrm{~s}+1)^{2}} & \frac{3.46 e^{-1.01 s}}{32 \mathrm{~s}+1} & \frac{-0.51 e^{-7.5 s}}{(32 \mathrm{~s}+1)^{2}} & \frac{1.68 e^{-2 s}}{(28 \mathrm{~s}+1)^{2}} \\
\frac{-1.06 e^{-22 s}}{(17 \mathrm{~s}+1)^{2}} & \frac{3.511 e^{-13 s}}{(12 \mathrm{~s}+1)^{2}} & \frac{4.41 e^{-1.01 s}}{16.2 \mathrm{~s}+1} & \frac{-5.38 e^{-0.5 s}}{17 \mathrm{~s}+1} \\
\frac{-5.73 e^{-2.5 s}}{(8 \mathrm{~s}+1)(50 \mathrm{~s}+1)} & \frac{4.32(25 \mathrm{~s}+1) e^{-0.01 s}}{(50 \mathrm{~s}+1)(5 \mathrm{~s}+1)} & \frac{-1.25 e^{-2.8 s}}{(43.6 \mathrm{~s}+1)(9 \mathrm{~s}+1)} & \frac{4.78 e^{-1.15 s}}{(48 \mathrm{~s}+1)(5 \mathrm{~s}+1)}
\end{array}\right)
$$

The three configurations to be compared are 3-3-3-2, 1-1-3-1 and 1-2-2-3. According to the criteria proposed in section 2.2, configuration 3-3-3-2 should be chosen because it has the smallest overshoots and settling times in its corresponding apparent processes $\mathrm{q}_{\mathrm{i}}(\mathrm{s})$. Its extra dynamics is given by $\mathrm{n}_{11}(\mathrm{~s})=\mathrm{e}^{-0.99 \mathrm{~s}}, \mathrm{n}_{22}(\mathrm{~s})=\mathrm{e}^{-2.3 \mathrm{~s}}, \mathrm{n}_{33}(\mathrm{~s})=\mathrm{e}^{-2.3 \mathrm{~s}}$ and $\mathrm{n}_{44}(\mathrm{~s})$ $=\mathrm{e}^{-3.8 \mathrm{~s}} /(0.2 \mathrm{~s}+1)$. No realizable configurations are available without extra dynamics; however, the configuration 1-1-3-1 is selected because it only needs an extra time delay associated with the third input. Therefore, its extra dynamics is given by $\mathrm{n}_{11}(\mathrm{~s})=1$, $\mathrm{n}_{22}(\mathrm{~s})=1, \mathrm{n}_{33}(\mathrm{~s})=\mathrm{e}^{-2.33 \mathrm{~s}}$ and $\mathrm{n}_{44}(\mathrm{~s})=1$. The third configuration 1-2-2-3 is selected as a bad case for the criteria of section 2.2. The associated apparent processes have the larger overshoots and settling times. In addition, an element with a RHP zero like (13) is needed to achieve realizability. The extra dynamics for this configuration is $\mathrm{n}_{11}(\mathrm{~s})=1$, $\mathrm{n}_{22}(\mathrm{~s})=\mathrm{e}^{-2.49 \mathrm{~s}} /(0.2 \mathrm{~s}+1), \mathrm{n}_{33}(\mathrm{~s})=\mathrm{e}^{-2.49 \mathrm{~s}} \cdot(-50.15 \mathrm{~s}+1) /((0.2 \mathrm{~s}+1) \cdot(-50.15 \mathrm{~s}+1))$ and $\mathrm{n}_{44}(\mathrm{~s})=\mathrm{e}^{-}$ $2.3 \mathrm{~s}$

Decoupler network $\mathrm{D}(\mathrm{s})$ and apparent processes $\mathrm{q}_{\mathrm{i}}(\mathrm{s})$ for these configurations are obtained following (16) and (17), respectively. For configuration 3-3-3-2, the results are shown in the $\mathrm{D}_{3332}$ matrix in (45) and (46). In a similar way, for configuration 1-1-3-1, the decoupler matrix $\mathrm{D}_{1131}$ and the apparent process are given by (47) and (48), respectively. The expressions (49) and (50) are the corresponding ones for configuration 1-2-2-3.

$$
\begin{aligned}
& \mathrm{D}_{3332}(\mathrm{~s})= \\
& \left(\begin{array}{c}
\frac{0.9102 s^{2}+0.03877 s+0.000579}{s^{2}+0.1052 s+0.001076} \\
\frac{-0.01232 s^{2}-0.002552 s+6.264 \cdot 10^{-5}}{s^{2}+0.05557 s+0.0005051} e^{-249 s} \\
e^{-0.99 s} \\
\frac{0.7914 s^{3}+0.203 s^{2}+0.01072 s+0.0001136}{s^{3}+0.2206 s^{2}+0.01456 s+0.0001429} e^{-1.5 s}
\end{array}\right. \\
& \mathrm{q}_{1}(\mathrm{~s})=\frac{-0.059 s^{2}+0.0127 s+5.87 \cdot 10^{-4}}{s^{2}+0.047 s+0.001734} e^{-1.19 s} \\
& \mathrm{q}_{2}(\mathrm{~s})=\frac{-0.1311 s^{2}+0.03275 s+0.00078}{s^{2}+0.0446 s+0.001075} e^{-3.5 s} \\
& \mathrm{q}_{3}(\mathrm{~s})=\frac{-0.1568 s^{2}+0.2258 s+0.00319}{s^{2}+0.08694 s+0.001638} e^{-2 s} \\
& \mathrm{q}_{4}(\mathrm{~s})=\frac{-0.01025 s^{2}-0.4427 s-0.1662}{s^{2}+0.2953 s+0.03164} e^{-2.5 s}
\end{aligned}
$$


$\mathrm{D}_{1131}(\mathrm{~s})=$
$\left(\begin{array}{c}1 \\ \frac{-0.00235 s^{2}-0.00505 s+0.000113}{s^{2}+0.03666 s+0.0004911} e^{-2.49 s} \\ \frac{1.094 s^{2}+0.1161 s+0.001186}{s^{2}+0.04278 s+0.0006385} e^{-0.99 s} \\ \frac{0.83 s^{3}+0.355 s^{2}+0.0233 s+0.000245}{s^{3}+0.288 s^{2}+0.01186 s+0.0001662} e^{-1.5 s}\end{array}\right.$
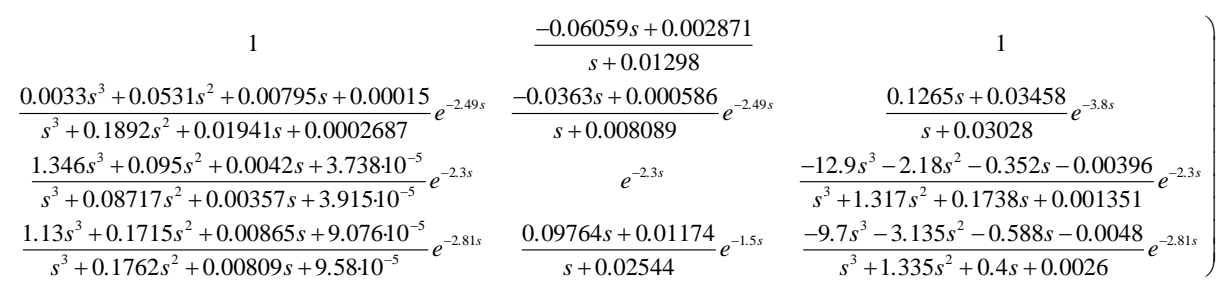

(47)

$\mathrm{q}_{1}(\mathrm{~s})=\frac{-0.2137 s^{2}+0.0292 s+3.993 \cdot 10^{-4}}{s^{2}+0.02852 s+6.346 \cdot 10^{-4}} e^{-1.19 s}$
$\mathrm{q}_{2}(\mathrm{~s})=\frac{-0.159 s^{2}+0.04372 s+5.113 \cdot 10^{-4}}{s^{2}+0.04444 s+7.38 \cdot 10^{-4}} e^{-3.5 s}$
$\mathrm{q}_{3}(\mathrm{~s})=\frac{-0.1568 s^{2}+0.2258 s+0.00319}{s^{2}+0.08694 s+0.001638} e^{-2 s}$
$\mathrm{q}_{4}(\mathrm{~s})=\frac{-0.5139 s^{2}+0.3401 s-0.2138}{s^{2}+1.237 s+0.03564} e^{-2.5 s}$

$\mathrm{D}_{1223}(\mathrm{~s})=$

$\left(\begin{array}{c}1 \\ \frac{-0.00235 s^{2}-0.00505 s+0.000113}{s^{2}+0.03666 s+0.0004911} e^{-2.49 s} \\ \frac{1.094 s^{2}+0.1161 s+0.001186}{s^{2}+0.04278 s+0.0006385} e^{-0.99 s} \\ \frac{0.83 s^{3}+0.355 s^{2}+0.0233 s+0.000245}{s^{3}+0.288 s^{2}+0.01186 s+0.0001662} e^{-1.5 s}\end{array}\right.$
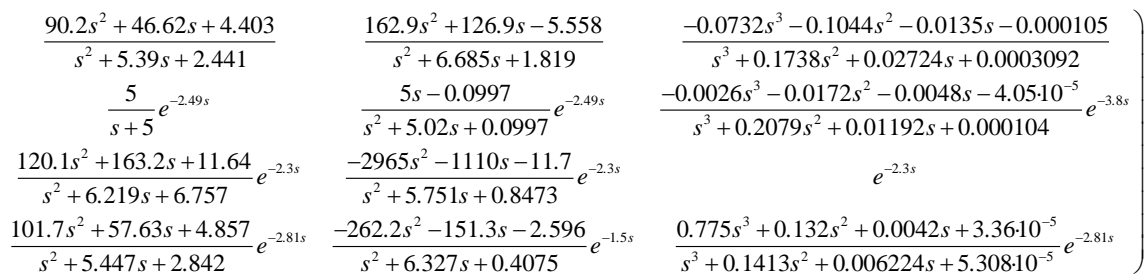

(49)

$\mathrm{q}_{1}(\mathrm{~s})=\frac{-0.2137 s^{2}+0.0292 s+3.993 \cdot 10^{-4}}{s^{2}+0.02852 s+6.346 \cdot 10^{-4}} e^{-1.19 s}$
$\mathrm{q}_{2}(\mathrm{~s})=\frac{0.02742 s^{2}+0.1085 s+0.001007}{s^{2}+0.04832 s+8.06 \cdot 10^{-4}} e^{-3.5 s}$
$\mathrm{q}_{3}(\mathrm{~s})=\frac{-64.51 s^{2}-23.81 s-0.2038}{s^{2}+0.08913 s+0.007574} e^{-2 s}$
$\mathrm{q}_{4}(\mathrm{~s})=\frac{-0.1613 s^{2}+0.04265 s+0.006778}{s^{2}+0.06822 s+0.003313} e^{-2.5 s}$

In each configuration, the parameters of the decentralized PI controller are tuned independently for the corresponding $\mathrm{q}_{\mathrm{i}}(\mathrm{s})$ according to [26] using a phase margin of $60^{\circ}$ as the specification in the four loops. The resulting PI parameters are listed in Table 4 with the performance indices of the three different configurations.

\section{INSERT HERE TABLE 4}

The closed loop system responses (outputs and control signals) of the three cases are depicted in Figure 7. There is a unit step change in each reference every $400 \mathrm{~min}$. All of them achieve almost perfect decoupling. Configuration 3-3-3-2 obtains the fastest responses with the smallest IAE indices. Configuration 1-1-3-1 has similar performance in the outputs $\mathrm{y}_{2}$ and $\mathrm{y}_{3}$, but its response is slower in outputs $\mathrm{y}_{1}$ and $\mathrm{y}_{4}$. Configuration 12-2-3 shows the worst performance in outputs $\mathrm{y}_{1}, \mathrm{y}_{2}$ and $\mathrm{y}_{3}$ with very slow responses. Consequently, its IAE indices are higher than those of the other configurations. In addition, it presents the highest peaks in the control signals. 
To investigate the robustness of the three controllers, a $\mu$-analysis similar to the previous example is performed. The selected weights are given by (51). Figure 8 shows the SSV for RS and RP for the different configurations. The RS is satisfied by all cases; however, the smallest peak value is obtained using configuration 3-3-3-2. The peak values of the other cases are shown in Table 4. The RP condition (42) is satisfied by configurations 1-1-3-1 and 1-2-2-3, and it is almost fulfilled by configuration 3-3-3-2, that presents a little peak of 1.02 around $0.1 \mathrm{rad} / \mathrm{min}$. Nevertheless, at low frequencies, configuration 3-3-3-2 obtains the smallest values.

$$
\begin{aligned}
& W_{I}(\mathrm{~s})=w_{I}(\mathrm{~s})=\frac{(0.225 \mathrm{~s}+0.15)}{22.5 s+1} \cdot I \\
& W_{P}(\mathrm{~s})=w_{P}(\mathrm{~s})=\frac{(\mathrm{s} / 2.6+0.001)}{s} \cdot I
\end{aligned}
$$

\section{INSERT HERE FIGURE 8}

\subsection{Nonlinear boiler-turbine model}

The boiler-turbine model developed in [32] is a third-order nonlinear multivariable system with great interactions, hard constraints and rate limits imposed on the actuators. The dynamics of the unit is given by (52)

$$
\begin{aligned}
& \dot{x}_{1}=-0.0018 u_{2} x_{1}^{9 / 8}+0.9 u_{1}-0.15 u_{3} \\
& \dot{x}_{2}=\left(0.073 u_{2}-0.016\right) x_{1}^{9 / 8}-0.1 x_{2} \\
& \dot{x}_{3}=\left(141 u_{3}-\left(1.1 u_{2}-0.19\right) x_{1}\right) / 85 \\
& y_{1}=x_{1} \\
& y_{2}=x_{2} \\
& y_{3}=0.05\left(0.13073 x_{3}+100 a_{c s}+q_{e} / 9-67.975\right) \\
& a_{c s}=\frac{\left(1-0.001538 x_{3}\right)\left(0.8 x_{1}-25.6\right)}{x_{3}\left(1.0394-0.0012304 x_{1}\right)} \\
& q_{e}=\left(0.854 u_{2}-0.147\right) x_{1}+45.59 u_{1}-2.514 u_{3}-2.096
\end{aligned}
$$

where state variables $x_{1}, x_{2}$ and $x_{3}$ denote the drum pressure $\left(\mathrm{kg} / \mathrm{cm}^{2}\right)$, power output (MW) and fluid density $\left(\mathrm{kg} / \mathrm{m}^{3}\right)$, respectively. The output $y_{3}$ is the drum water level (m) regarding the operating reference level. The inputs $u_{1}, u_{2}$ and $u_{3}$ are the valve positions for fuel flow, steam control, and feed-water flow, respectively. Because of actuator limitations, the control inputs are subjected to the constraints given in (53).

$$
\begin{aligned}
& 0 \leq u_{i} \leq 1(i=1,2,3) \\
& \left|\dot{u}_{1}\right| \leq 0.007 \\
& -2 \leq \dot{u}_{2} \leq 0.02 \\
& \left|\dot{u}_{3}\right| \leq 0.05
\end{aligned}
$$

There are several typical operating points of the model in (52); however, the linear control design for the unit found in literature usually takes the linearized model at the operating point $x^{0}=\left[\begin{array}{llll}108 & 66.65 & 428\end{array}\right]^{\mathrm{T}}, u^{0}=\left[\begin{array}{llll}0.34 & 0.69 & 0.433\end{array}\right]^{\mathrm{T}}$ and $y^{0}=\left[\begin{array}{lll}10866.65 & 0\end{array}\right]^{\mathrm{T}}$. The obtained linearized model $\mathrm{G}_{\mathrm{B}}(\mathrm{s})$ to carry out the design is given by (54). 


$$
\mathrm{G}_{\mathrm{B}}(\mathrm{s})=\left(\begin{array}{ccc}
\frac{358.7}{398.6 s+1} & \frac{249.1}{(398.6 s+1)(10 \mathrm{~s}+1)} & \frac{0.0113(34.58 s+1)(258.33 s-1)}{(398.6 s+1) \mathrm{s}} \\
\frac{-139.1}{398.6 s+1} & \frac{44.96(1255.3 s+1)}{(398.6 s+1)(10 \mathrm{~s}+1)} & \frac{0.0022(1428.6 s+1)(65.15 s-1)}{(398.6 s+1) \mathrm{s}} \\
\frac{-59.79}{398.6 s+1} & \frac{-41.49}{(398.6 s+1)(10 \mathrm{~s}+1)} & \frac{-0.0097(282.57 s+1)(2.03 s-1)}{(398.6 s+1) \mathrm{s}}
\end{array}\right)^{\mathrm{T}}
$$

In this case with no time delays, it is not necessary to approximate $\left|G_{B}(s)\right|$ or adjG(s). According to the expressions in (15), two configurations (3-2-1 and 3-2-3) are realizable without extra dynamics. Because of necessary extra dynamics with RHP zeros like (13), configurations 1-b-c, a-1-c and a-3-c (with a, b, c being 1, 2 or 3) are discarded. The other possible apparent processes do not have serious problems about undershoot or overshoot; therefore, the settling time is the criterion to decide. Finally, configuration 22-1 is preferred because that configuration is verified to have better performance with smaller settling times and simpler extra dynamics. Its extra dynamics are given by $\mathrm{n}_{11}(\mathrm{~s})$ $=1 /(0.4 \mathrm{~s}+1), \mathrm{n}_{22}(\mathrm{~s})=1$ and $\mathrm{n}_{33}(\mathrm{~s})=1$. The corresponding decoupler network $\mathrm{D}(\mathrm{s})$ and apparent processes $\mathrm{q}_{\mathrm{i}}(\mathrm{s})$ are expressed in (55) and (56), respectively. The element $\mathrm{D}(2,1)$ has been approximated to unity and element $\mathrm{D}(2,3)$ to zero.

$$
\begin{aligned}
& \mathrm{D}(\mathrm{s})=\left(\begin{array}{ccc}
\frac{280 s^{2}-144.8 s-0.1225}{s^{2}+2.776 s+0.6908} & \frac{-3.215 s+0.146}{s+0.2764} & 1 \\
1 & 1 & 0 \\
\frac{5078 s^{2}+73.17 s+0.01363}{s^{2}+2.776 s+0.6908} & \frac{-21.62 s+0.2329}{s+0.2764} & 6
\end{array}\right) \quad(55) \\
& \mathrm{q}_{1}(\mathrm{~s})=\frac{-509.7 s-140.9}{s^{2}+2.776 s+0.6908} \\
& \mathrm{q}_{2}(\mathrm{~s})=\frac{14.16}{s+0.1} \\
& \mathrm{q}_{3}(\mathrm{~s})=\frac{0.1695 s+0.04684}{s}
\end{aligned}
$$

To finish the design of the proposed simplified decoupling control for $\mathrm{G}_{\mathrm{B}}(\mathrm{s})$, three PI controllers are tuned independently for the previous apparent processes. The tuning was performed according to [25] using closed loop time constants equal to 20, 10 and 20 seconds. The PI parameters for the controllers are:

$$
K_{P}=\left(\begin{array}{c}
-9.8 \cdot 10^{-5} \\
0.0071 \\
1.0684
\end{array}\right) \quad K_{I}=\left(\begin{array}{c}
-2.45 \cdot 10^{-4} \\
7.1 \cdot 10^{-4} \\
0.0267
\end{array}\right)
$$

Subsequently, the elements of the centralized control K(s) are obtained according to (19) and reduced to PI controllers. The resulting PI parameters are: 


$$
\begin{aligned}
K_{P} & =\left(\begin{array}{ccc}
0.0512 & -0.0059 & 1.0684 \\
-9.8 \cdot 10^{-5} & 0.0071 & 0 \\
0.0259 & -0.0517 & 6.4104
\end{array}\right) \\
K_{I} & =\left(\begin{array}{ccc}
0.0434 & 0.3751 & 26.71 \\
-0.245 & 0.71 & 0 \\
-0.0048 & 0.5983 & 160.26
\end{array}\right) / 1000
\end{aligned}
$$

Next, we analyze the performance of the proposed multivariable PI controllers in simulation using the nonlinear model of the boiler-turbine in (52). In the simulation, the power output reference is increased from 66.65 to $120 \mathrm{MW}$ at $\mathrm{t}=100 \mathrm{~s}$; at $\mathrm{t}=1000 \mathrm{~s}$, the drum pressure reference is increased from 108 to $120 \mathrm{~kg} / \mathrm{cm}^{2}$. This test is performed assuming three different cases: first, the ideal case without input constraints is assumed; second, the case with input constraints in (53) and without anti-windup scheme is assumed; third, the case with input constraints in (53) and the anti-windup scheme proposed in subsection 3.4 for case $3 \times 3$ is assumed.

Figure 9 shows the simulation results. In the ideal case, the references are reached very fast with practically perfect decoupling. However, after the first step change in the second reference, the second control signal $\mathrm{u}_{2}$ is out of range; the signal only returns to range when the second step change in the first reference takes place. In the second case, the first and second references are not reached after the first reference step change because the control signal $\mathrm{u}_{2}$ is saturated. This fact provokes windup in this signal, and after the second reference change at $t=1000 \mathrm{~s}, \mathrm{u}_{2}$ does not change until $2000 \mathrm{~s}$ later. Consequently, the time to reach the first reference is very late. This response is improved significantly over the implementation of the anti-windup scheme in Figure 4 for the $3 \times 3$ case. Using this scheme, the second reference is not reached at the beginning; however, the control signal $\mathrm{u}_{2}$ reacts very quickly after the second references step because the windup problem has been avoided, and all of the references are reached sooner. Although simulations using the proposed simplified decoupling control $\mathrm{D}(\mathrm{s}) \cdot \mathrm{C}(\mathrm{s})$ are not shown, similar responses are obtained in all cases. The anti-windup scheme is implemented according to scheme proposed in [30] for the case $3 \times 3$.

\section{INSERT HERE FIGURE 9}

\subsection{Experimental process: quadruple tank system}

The experimental process is a quadruple tank plant [33] in the lab of the Computer Science Department of the University of Cordoba. The outputs are the level of the lower tanks, which are between 0 and $35 \mathrm{~cm}$; the inputs are the flow references of the secondary control loops that regulate the operation of the pumps, which are between 0 and $200 \mathrm{~cm}^{3} / \mathrm{s}$. The plant was configured to show interaction problems with a multivariable RHP zero. The process was identified around the operation point $h=[17$ $18] \mathrm{cm}$ and $u=\left[\begin{array}{lll}135 & 135\end{array} \mathrm{~cm}^{3} / \mathrm{s}\right.$. The resultant model is given by (59). It has an RGA of -0.21 and a multivariable RHP zero at $s=1 / 164.67$.

$$
\mathrm{G}_{\mathrm{T}}(\mathrm{s})=\left(\begin{array}{cc}
\frac{0.175}{191.5 s+1} & \frac{0.402}{(170.5 s+1)(260.7 s+1)} \\
\frac{0.385}{(165 s+1)(240.4 s+1)} & \frac{0.154}{178.6 s+1}
\end{array}\right)
$$


Because of the relative degrees, configuration 1-2 must be chosen to apply simplified decoupling without adding extra dynamics. Then, the following decoupler matrix (60) and apparent process (61) are obtained according to Table 1. In this case, approximation is not necessary for $\mathrm{D}(\mathrm{s})$.

$$
\begin{aligned}
& \mathrm{D}(\mathrm{s})=\left(\begin{array}{cc}
1 & \frac{-2.297(191.5 s+1)}{(170.5 s+1)(260.7 s+1)} \\
\frac{-2.5(178.6 s+1)}{(165 s+1)(240.4 s+1)} & 1
\end{array}\right) \\
& \mathrm{Q}(\mathrm{s})=\left(\begin{array}{cc}
\frac{7.843 \cdot 10^{-6}(164.67 s-1)}{s^{2}+0.005445 s+9.47 \cdot 10^{-6}} & 0 \\
0 & \frac{7.275 \cdot 10^{-6}(164.67 s-1)}{s^{2}+0.00562 s+9.98 \cdot 10^{-6}}
\end{array}\right)
\end{aligned}
$$

After determining the decoupler network, the parameters of a decentralized PI controller are independently tuned for the corresponding $\mathrm{q}_{\mathrm{i}}(\mathrm{s})$ according to [26] using a phase margin of $60^{\circ}$ as specification in both loops. In this way, the proposed simplified decoupling control is obtained. The centralized control by simplified decoupling $\mathrm{K}(\mathrm{s})$ is calculated according to (19), and its elements are approximated to PI controllers to achieve the proposed multivariable PI control by simplified decoupling (MV-PI). Only its off-diagonal elements need to be approximated to PI structure. The parameters of the resulting PI controllers for both methodologies proposed previously are shown in Table 5.

\section{INSERT HERE TABLE 5}

Figure 10 shows the resultant response of the proposed controllers for a step of $4 \mathrm{~cm}$ in the references. For comparison, the response of a decentralized PI controller is also shown. This controller is tuned according to the iterative method in [2] using a phase margin of $60^{\circ}$ as specification in both loops. According to the RGA, the chosen pairing is $\mathrm{y}_{1}-\mathrm{u}_{2}$ and $\mathrm{y}_{2}-\mathrm{u}_{1}$. The PI parameters are listed in Table 5.

\section{INSERT HERE FIGURE 10}

With simplified decoupling, perfect decoupling is practically achieved. Using the proposed multivariable PI control there are some little interactions, while the decentralized control presents important couplings in both loops. However, the improved decoupling performance of both proposed methodologies is obtained at the expensive of closed loop bandwidth because the RHP zero imposes an upper limit on this bandwidth. For this reason, the decentralized control reaches the references faster. In this process, there is a trade-off between the undershoot in the response of the considered loop and the interaction with the other loop.

\section{Conclusions}

A generalization of simplified decoupling technique for $n \times n$ processes has been developed in this work. Different configurations can be demonstrated by a matrix 
formulation depending on the decoupler elements that are set to unity. Thus, it is possible to select the proper configuration considering different aspects such as the complexity of the corresponding decoupler elements or the response of apparent processes. The realizability conditions for each configuration were illustrated, and the expressions of simplified decoupling for $2 \times 2$ and $3 \times 3$ processes are shown in more detail. The general formulation of centralized control by simplified decoupling is derived from the previous methodology. Then, the centralized control is proposed as the second methodology after a reduction to multivariable PID control.

Several design considerations, such as an approximation method and model reduction have been discussed in this work. In addition, anti-windup schemes for the developed methodologies have been proposed from a practical point of view. These schemes, which can be implemented in distributed control systems, have been tested in simulation.

Although the proposed methodologies are more difficult than inverted decoupling to apply to high dimensional systems, their utilization is justified in those processes with multivariable RHP zeros because inverted decoupling cannot be applied. This has been illustrated with several simulation examples of sizes $3 \times 3$ and $4 \times 4$. Comparisons with other methods have demonstrated that the proposed methodologies achieve similar or better performance. Additionally, an experimental quadruple tank system was used to verify the effectiveness of these methodologies.

\section{Acknowledgments}

This work was supported by the Autonomous Government of Andalusia (Spain), under the Excellence Project P10-TEP-6056. This support is very gratefully acknowledged.

\section{References}

[1] F. C. Shinskey, Sistemas de control de procesos. Aplicación, diseño y sintonización. Tomo 1, McGrawhill, 1996.

[2] F. Vázquez, F. Morilla, S. Dormido, An iterative method for tuning decentralized PID controllers, Proceedings of the 14th IFAC World Congress (1999) 491-496.

[3] H. P. Huang, J. C. Jeng, C. H. Chiang, W. Pan, A direct method for multi-loop PI/PID controller design, J. Process Control 13 (2003) 769-786.

[4] M. Lee, K. Lee, C. Kim, J. Lee, Analytical design of multiloop PID controllers for desired closed-loop responses, AIChE J. 50 (2004) 1631-1635.

[5] Q. Xiong, W. J. Cai, Effective transfer function method for decentralized control system design of multi-input multi-output processes, J. Process Control 16 (2006) 773-784.

[6] Q. W. Wang, Decoupling Control, Lecture Notes in Control and Information Sciences, 285, Springer-Verlag, 2003.

[7] B. Ogunnaike, W. Harmor, Process dynamics, modelling and control, Oxford University Press, 1994.

[8] K. J. Åström, K. H. Johansson, Q. W. Wang, Design of decoupled PI controller for two-by-two systems, IEE Proc. Contr. Theor. Appl. 149 (2002) 74-81.

[9] K. Waller, Decoupling in distillation, AIChE J. 20 (1974) 592-594.

[10] P. Nordfeldt, T. Hägglund, Decoupler and PID controller design of TITO systems, J. Process Control 16, (2006) 923-936.

[11] S. Tavakoli, I. Griffin, P. J. Fleming, Tuning of decentralised PI (PID) control for TITO processes, Control Eng. Pract. 14 (2006) 1069-1080.

[12] W. J. Cai, W. Ni, M. J. He, C. Y. Ni, Normalized Decoupling - A new approach for MIMO process control system design, Ind. Eng. Chem. Res. 47 (2008) 7347-7356. 
[13] B. T. Jevtovic, M. R. Matausek, PID controller design of TITO system based on ideal decoupler, J. Process Control 20 (2010) 869-876.

[14] J. Garrido, F. Vázquez, F. Morilla, An extended approach of inverted decoupling, J. Process Control 21 (2011) 55-68.

[15] J. Garrido, F. Vázquez, F. Morilla, T. Hägglund, Practical advantages of inverted decoupling, Proc. IMechE Part I: J. Systems and Control Engineering 225 (2011) 977-992.

[16] J. Lieslehto, MIMO controller design using SISO controller design methods, Proceedings of the 13th IFAC World Congress (1996) 169-173.

[17] Q. W. Wang, B. Zou, T. Lee, Q. Bi, Auto-tuning of Multivariable PID Controllers from Decentralized Feedback, Automatica 33 (1997) 319-330.

[18] Q. W. Wang, Y. Zhang, M. S. Chiu, Decoupling internal model control for multivariable systems with multiple time delays, Chem. Eng. Sci. 57 (2002) 115-124.

[19] Q. W. Wang, Y. Zhang, M. S. Chiu, None-interacting control design for multivariable industrial processes, J. Process Control 13 (2003) 253-265.

[20] T. Liu, W. Zhang, F. Gao, Analytical decoupling control strategy using a unity feedback control structure for MIMO processes with time delays, J. Process Control 17 (2007) 173-186.

[21] Q. Xiong, W. J. Cai, M. J. He, Equivalent transfer function method for PI/PID controller design of MIMO processes, J. Process Control 17 (2007) 665-673.

[22] F. Morilla, F. Vázquez, J. Garrido, Centralized PID Control by Decoupling for TITO Processes, Proceedings of 13th IEEE International Conference on Emerging Technologies and Factory Automation (2008) 1318-1325.

[23] J. Garrido, F. Morilla, F. Vázquez, Centralized PID Control by Decoupling of a Boiler-Turbine Unit, 10th European Control Conference, Budapest (2009) 4007-4012.

[24] S. Skogestad, I. Postlethwaite, Multivariable Feedback Control: Analysis and Design, John Wiley \& sons, 2005.

[25] D. E. Rivera, M. Morari, S. Skogestad, Internal Model Control. 4. PID controller design, Ind. Eng. Chem. Process Des. Dev. 25 (1986) 252-265.

[26] F. Morilla, S. Dormido, Methodologies for the tuning of PID controllers in the frequency domain, Proceedings of the PID'00 IFAC Workshop on Digital Control: Past, present and future of PID Control (2000) 155-160.

[27] T. Hägglund, K. J. Åström, Revisiting the Ziegler-Nichols step response method for PID control, J. Process Control 14 (2004) 635-650.

[28] R. Pintelon, P. Guillaume, Y. Rolain, J. Schoukens, H. Van hamme, Parametric identification of transfer functions in the frequency domain - A survey, IEEE Trans. Automat. Control 39 (1994) 2245-2260.

[29] K. J. Aström, T. Hägglund, Advanced PID control, ISA - The Instrumentation, Systems and Automation Society, 2006.

[30] E. Gagnon, A. Pomerleau, A. Desbiens, Simplified, ideal or inverted decoupling?, ISA Trans. 37 (1998) 265-276.

[31] W. Luyben, Simple method for tuning SISO controllers in multivariable systems, Ind. Eng. Chem. Process Des. Dev. 25 (1986) 654-660.

[32] R. D. Bell, K. J. Aström, Dynamic models for boiler-turbine-alternator units: data logs and parameter estimation for a $160 \mathrm{MW}$ unit, Lund Institute of Technology, Sweden, Report TFRT3192, 1987.

[33] K. H. Johansson, The quadruple-tank process: a multivariable laboratory process with an adjustable zero, IEEE Trans. Control Syst. Technol. 8 (2000) 456-465. 


\begin{tabular}{|c|c|c|c|c|c|}
\hline Configuration & $\mathrm{D}(\mathrm{s})$ & \multicolumn{2}{|c|}{$\mathrm{K}(\mathrm{s})$} & \multicolumn{2}{|c|}{$\mathrm{Q}(\mathrm{s})$} \\
\hline $1-1$ & $\left.\begin{array}{cc}1 & 1 \\
\frac{-g_{21}}{g_{22}} & \frac{-g_{11}}{g_{12}}\end{array}\right)$ & $\left(\begin{array}{c}\mathrm{k}_{11} \\
\frac{-\mathrm{g}_{21}}{\mathrm{~g}_{22}} \cdot \mathrm{k}_{11}\end{array}\right.$ & $\left.\begin{array}{c}\mathrm{k}_{12} \\
\frac{-\mathrm{g}_{11}}{\mathrm{~g}_{12}} \cdot \mathrm{k}_{12}\end{array}\right)$ & $\begin{array}{c}g_{11}-\frac{g_{12} \cdot g_{21}}{g_{22}} \\
0\end{array}$ & $\begin{array}{c}0 \\
g_{21}-\frac{g_{11} \cdot g_{22}}{g_{12}}\end{array}$ \\
\hline $1-2$ & $\left.\begin{array}{cc}1 & \frac{-g_{12}}{g_{11}} \\
\frac{-g_{21}}{g_{22}} & 1\end{array}\right)$ & $\left(\begin{array}{c}\mathrm{k}_{11} \\
\frac{-\mathrm{g}_{21}}{\mathrm{~g}_{22}} \cdot \mathrm{k}_{11}\end{array}\right.$ & $\begin{array}{c}\frac{-\mathrm{g}_{12}}{\mathrm{~g}_{11}} \cdot \mathrm{k}_{22} \\
\mathrm{k}_{22}\end{array}$ & $\begin{array}{c}g_{11}-\frac{g_{12} \cdot g_{21}}{g_{22}} \\
0\end{array}$ & $\begin{array}{c}0 \\
\mathrm{~g}_{22}-\frac{\mathrm{g}_{12} \cdot \mathrm{g}_{21}}{\mathrm{~g}_{11}}\end{array}$ \\
\hline $2-1$ & $\left.\begin{array}{cc}\frac{-g_{22}}{g_{21}} & 1 \\
1 & \frac{-g_{11}}{g_{12}}\end{array}\right)$ & $\left(\begin{array}{c}\frac{-\mathrm{g}_{22}}{\mathrm{~g}_{21}} \cdot \mathrm{k}_{21} \\
\mathrm{k}_{21}\end{array}\right.$ & $\begin{array}{c}\mathrm{k}_{12} \\
\frac{-\mathrm{g}_{11}}{\mathrm{~g}_{12}} \cdot \mathrm{k}_{12}\end{array}$ & $\begin{array}{c}\mathrm{g}_{12}-\frac{\mathrm{g}_{11} \cdot \mathrm{g}_{22}}{\mathrm{~g}_{21}} \\
0\end{array}$ & $\begin{array}{c}0 \\
g_{21}-\frac{g_{11} \cdot g_{22}}{g_{12}}\end{array}$ \\
\hline $2-2$ & $\left.\begin{array}{cc}\frac{-g_{22}}{g_{21}} & \frac{-g_{12}}{g_{11}} \\
1 & 1\end{array}\right)$ & $\left(\begin{array}{c}\frac{-g_{22}}{g_{21}} \cdot k_{21} \\
k_{21}\end{array}\right.$ & $\left.\begin{array}{c}\frac{-g_{12}}{g_{11}} \cdot k_{22} \\
k_{22}\end{array}\right)$ & $\begin{array}{c}\mathrm{g}_{12}-\frac{\mathrm{g}_{11} \cdot \mathrm{g}_{22}}{\mathrm{~g}_{21}} \\
0\end{array}$ & $\begin{array}{c}0 \\
g_{22}-\frac{g_{12} \cdot g_{21}}{g_{11}}\end{array}$ \\
\hline
\end{tabular}




\begin{tabular}{|c|c|c|c|c|c|c|c|c|c|}
\hline Configuration & & $\mathrm{D}(\mathrm{s})$ & & & $\mathrm{K}(\mathrm{s})$ & & & $\mathrm{Q}(\mathrm{s})$ & \\
\hline $1-1-1$ & $\begin{array}{c}1 \\
\frac{\operatorname{adjG}_{21}}{\operatorname{adjG}_{11}} \\
\frac{\operatorname{adjG} G_{31}}{\operatorname{adjG}_{11}}\end{array}$ & $\begin{array}{c}1 \\
\frac{\operatorname{adjG}_{22}}{\operatorname{adjG}_{12}} \\
\frac{\operatorname{adjG} G_{32}}{\operatorname{adjG}_{12}}\end{array}$ & $\begin{array}{c}1 \\
\frac{\operatorname{adjG}_{23}}{\operatorname{adjG} G_{13}} \\
\frac{\operatorname{adjG} G_{33}}{\operatorname{adjG}_{13}}\end{array}$ & $\begin{array}{c}\mathrm{k}_{11} \\
\frac{\operatorname{adjG}_{21}}{\operatorname{adjG}_{11}} \cdot \mathrm{k}_{11} \\
\frac{\operatorname{adjG}_{31}}{\operatorname{adjG}_{11}} \cdot \mathrm{k}_{11}\end{array}$ & $\begin{array}{c}\mathrm{k}_{12} \\
\frac{\operatorname{adjG}_{22}}{\operatorname{adjG}_{12}} \cdot \mathrm{k}_{12} \\
\frac{\operatorname{adjG}_{32}}{\operatorname{adjG}_{12}} \cdot \mathrm{k}_{12}\end{array}$ & $\begin{array}{c}\mathrm{k}_{13} \\
\frac{\operatorname{adjG}_{23}}{\operatorname{adjG}_{13}} \cdot \mathrm{k}_{13} \\
\frac{\operatorname{adjG}_{33}}{\operatorname{adjG}_{13}} \cdot \mathrm{k}_{13}\end{array}$ & $\begin{array}{c}\frac{|\mathrm{G}|}{\operatorname{adj}_{11}} \\
0\end{array}$ & $\begin{array}{c}0 \\
\frac{|\mathrm{G}|}{\operatorname{adjG}_{12}} \\
0\end{array}$ & $\begin{array}{c}0 \\
0 \\
\frac{|\mathrm{G}|}{\operatorname{adjG}_{13}}\end{array}$ \\
\hline $1-2-3$ & $\begin{array}{c}1 \\
\frac{\operatorname{adjG}_{21}}{\operatorname{adjG}_{11}} \\
\frac{\operatorname{adjG}_{31}}{\operatorname{adjG}_{11}}\end{array}$ & $\begin{array}{c}\frac{\operatorname{adjG}_{12}}{\operatorname{adjG}_{22}} \\
1 \\
\frac{\operatorname{adjG}_{32}}{\operatorname{adjG}_{22}}\end{array}$ & $\begin{array}{c}\frac{\operatorname{adjG} G_{13}}{\operatorname{adjG} G_{33}} \\
\frac{\operatorname{adjG}_{23}}{\operatorname{adjG} G_{33}} \\
1\end{array}$ & $\begin{array}{c}\mathrm{k}_{11} \\
\frac{\operatorname{adjG}_{21}}{\operatorname{adjG}_{11}} \cdot \mathrm{k}_{11} \\
\frac{\operatorname{adjG}_{31}}{\operatorname{adjG}_{11}} \cdot \mathrm{k}_{11}\end{array}$ & $\begin{array}{c}\frac{\operatorname{adjG}_{12}}{\operatorname{adjG}_{22}} \cdot \mathrm{k}_{22} \\
\mathrm{k}_{22} \\
\frac{\operatorname{adjG}_{32}}{\operatorname{adjG}_{22}} \cdot \mathrm{k}_{22}\end{array}$ & $\begin{array}{c}\frac{\operatorname{adjG}_{13}}{\operatorname{adjG}_{33}} \cdot k_{33} \\
\frac{\operatorname{adjG}_{23}}{\operatorname{adjG}_{33}} \cdot k_{33} \\
k_{33}\end{array}$ & $\begin{array}{c}\frac{|G|}{\operatorname{adjG}_{11}} \\
0\end{array}$ & $\begin{array}{c}0 \\
\frac{|\mathrm{G}|}{\operatorname{adjG}_{22}} \\
0\end{array}$ & $\begin{array}{c}0 \\
0 \\
\frac{|G|}{\operatorname{adjG}_{33}}\end{array}$ \\
\hline $2-2-1$ & $\begin{array}{c}\frac{\operatorname{adjG}_{11}}{\operatorname{adjG}_{21}} \\
1 \\
\frac{\operatorname{adjG}_{31}}{\operatorname{adjG}_{21}}\end{array}$ & $\begin{array}{c}\frac{\operatorname{adjG}_{12}}{\operatorname{adjG}_{22}} \\
1 \\
\frac{\operatorname{adjG}_{32}}{\operatorname{adjG}_{22}}\end{array}$ & $\begin{array}{c}1 \\
\frac{\operatorname{adjG}_{23}}{\operatorname{adjG}_{13}} \\
\frac{\operatorname{adjG}_{33}}{\operatorname{adjG}_{13}}\end{array}$ & $\begin{array}{c}\frac{\operatorname{adjG}_{11}}{\operatorname{adjG}_{21}} \cdot \mathrm{k}_{21} \\
\mathrm{k}_{21} \\
\frac{\operatorname{adjG}_{31}}{\operatorname{adjG}_{21}} \cdot \mathrm{k}_{21}\end{array}$ & $\begin{array}{c}\frac{\operatorname{adjG}_{12}}{\operatorname{adjG}_{22}} \cdot k_{22} \\
k_{22} \\
\frac{\operatorname{adjG}_{32}}{\operatorname{adjG}_{22}} \cdot k_{22}\end{array}$ & $\begin{array}{c}\mathrm{k}_{13} \\
\frac{\operatorname{adjG}_{23}}{\operatorname{adjG}_{13}} \cdot \mathrm{k}_{13} \\
\frac{\operatorname{adjG}_{33}}{\operatorname{adjG}_{13}} \cdot \mathrm{k}_{13}\end{array}$ & $\begin{array}{c}\frac{|G|}{\operatorname{adjG}_{21}} \\
0\end{array}$ & $\begin{array}{c}0 \\
\frac{|\mathrm{G}|}{\operatorname{adjG}_{22}} \\
0\end{array}$ & $\begin{array}{c}0 \\
\frac{|G|}{\operatorname{adjG}_{13}}\end{array}$ \\
\hline & & $\cdots$ & & & & & & & \\
\hline
\end{tabular}


Table 3 - PID parameters and indices for example 1

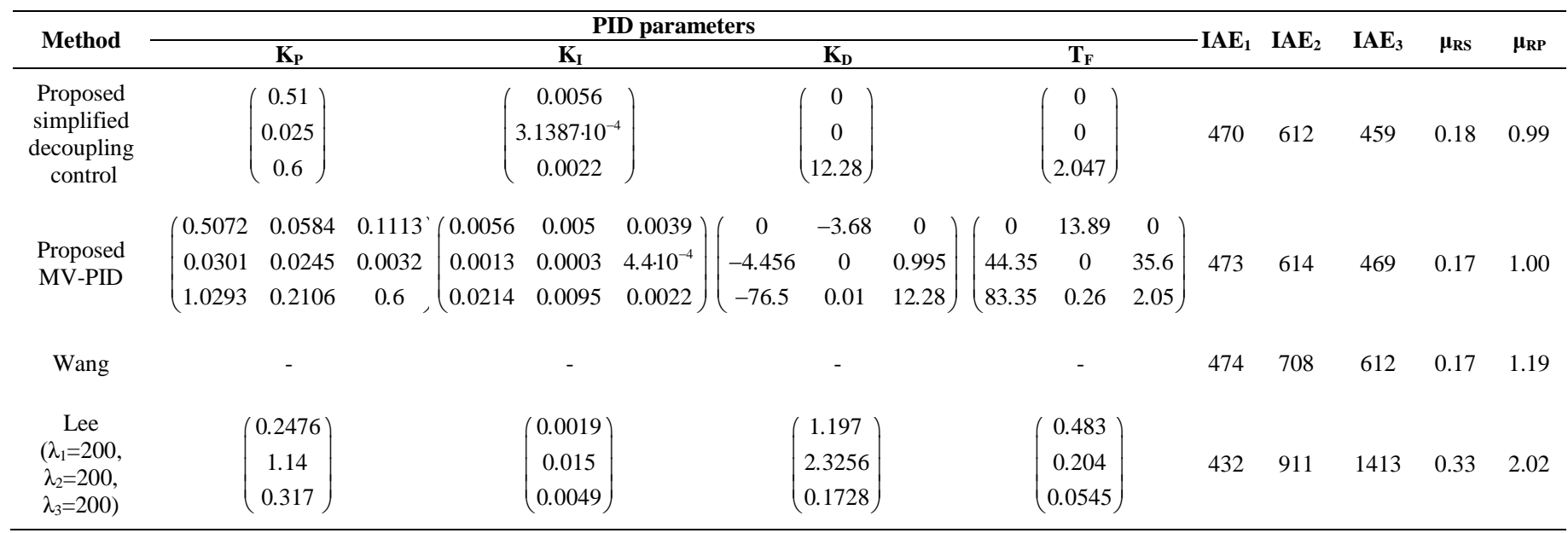


Table 4 - PID parameters and indices for example 2

\begin{tabular}{|c|c|c|c|c|c|c|c|c|c|c|c|c|c|c|}
\hline \multirow{2}{*}{ Configuration } & \multicolumn{8}{|c|}{ PI parameters } & \multirow{2}{*}{$\mathbf{I A E}_{1}$} & \multirow{2}{*}{$\mathbf{I A E}_{2}$} & \multirow{2}{*}{$\mathbf{I A E}_{3}$} & \multirow{2}{*}{$\mathbf{I A E}_{4}$} & \multirow[b]{2}{*}{$\mu_{\mathrm{RS}}$} & \multirow[b]{2}{*}{$\mu_{\mathrm{RP}}$} \\
\hline & $K_{p l}$ & $K_{p 2}$ & $K_{p 3}$ & $K_{p 4}$ & $T_{i 1}$ & $T_{i 2}$ & $T_{i 3}$ & $T_{i 4}$ & & & & & & \\
\hline $3-3-3-2$ & 3.83 & 1.58 & 0.76 & -0.009 & 32.8 & 30.8 & 12.1 & 0.77 & 29.5 & 30.8 & 19.6 & 24.1 & 0.18 & 1.02 \\
\hline $1-1-3-1$ & 1.5 & 1.45 & 0.76 & -0.104 & 40 & 26.5 & 12.1 & 15.2 & 46.8 & 31.2 & 20.7 & 41.5 & 0.23 & 0.96 \\
\hline $1-2-23$ & 1.5 & 0.09 & -0.002 & 0.27 & 40 & 5.2 & 2.4 & 14.6 & 48.2 & 48.3 & 49.63 & 30.9 & 0.21 & 0.96 \\
\hline
\end{tabular}


Table 5 - PI parameters for the quadruple tank process.

\begin{tabular}{ccc}
\hline \multirow{2}{*}{ Method } & \multicolumn{3}{c}{ PI parameters } \\
\cline { 2 - 3 }$K_{P}$ & $T_{I}$ \\
\hline $\begin{array}{c}\text { Proposed } \\
\text { simplified } \\
\text { decoupling }\end{array}$ & $\left(\begin{array}{cc}-1.09 & 0 \\
0 & -1.23\end{array}\right)$ & $\left(\begin{array}{cc}582 & 0 \\
0 & 572\end{array}\right)$ \\
$\begin{array}{c}\text { Proposed } \\
\text { MV-PI }\end{array}$ & $\left(\begin{array}{cc}-1.09 & 1.63 \\
1.64 & -1.23\end{array}\right)$ & $\left(\begin{array}{cc}582 & 332 \\
356 & 572\end{array}\right)$ \\
$\begin{array}{c}\text { Decentralized } \\
\left(\mathrm{y}_{1}-\mathrm{u}_{2}\right),\left(\mathrm{y}_{2}-\mathrm{u}_{1}\right)\end{array}$ & $\left(\begin{array}{cc}0 & 3.96 \\
4.92 & 0\end{array}\right)$ & $\left(\begin{array}{cc}0 & 420 \\
432 & 0\end{array}\right)$ \\
\hline
\end{tabular}




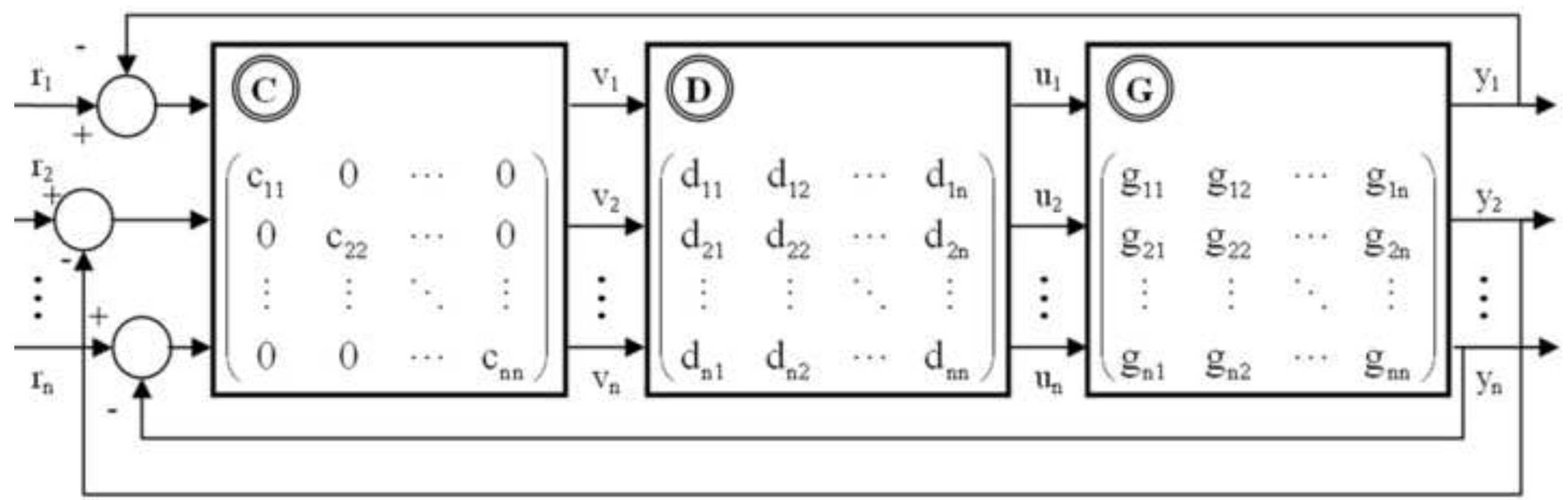




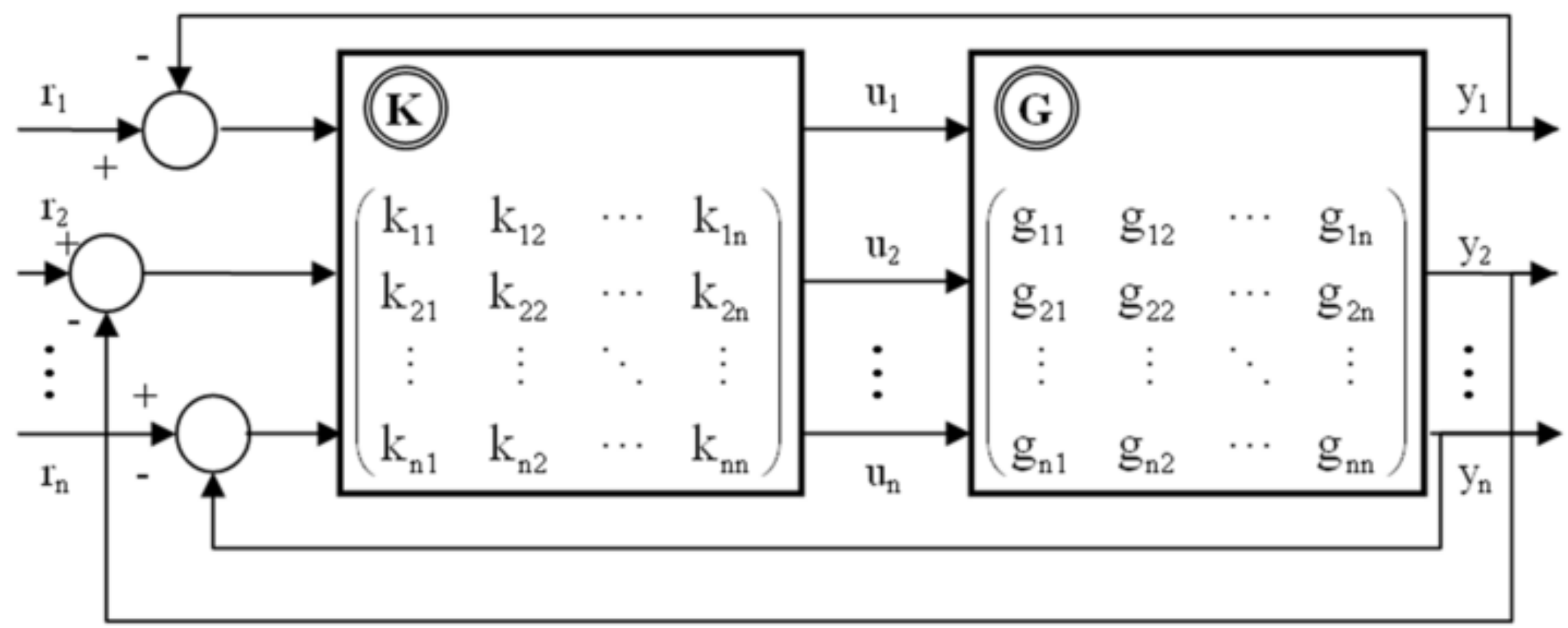


Figure 3. Bode plots of expression (23) colour

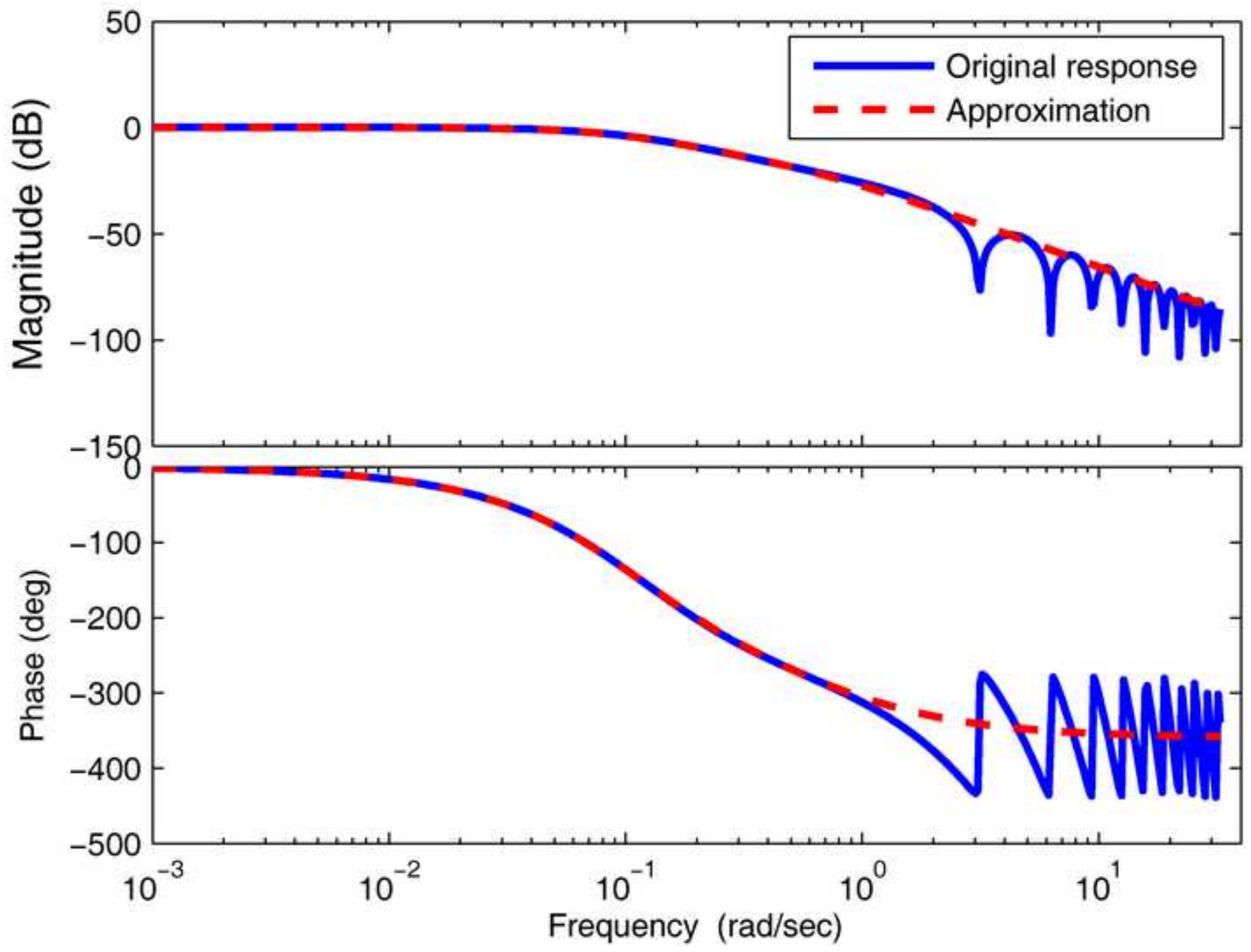




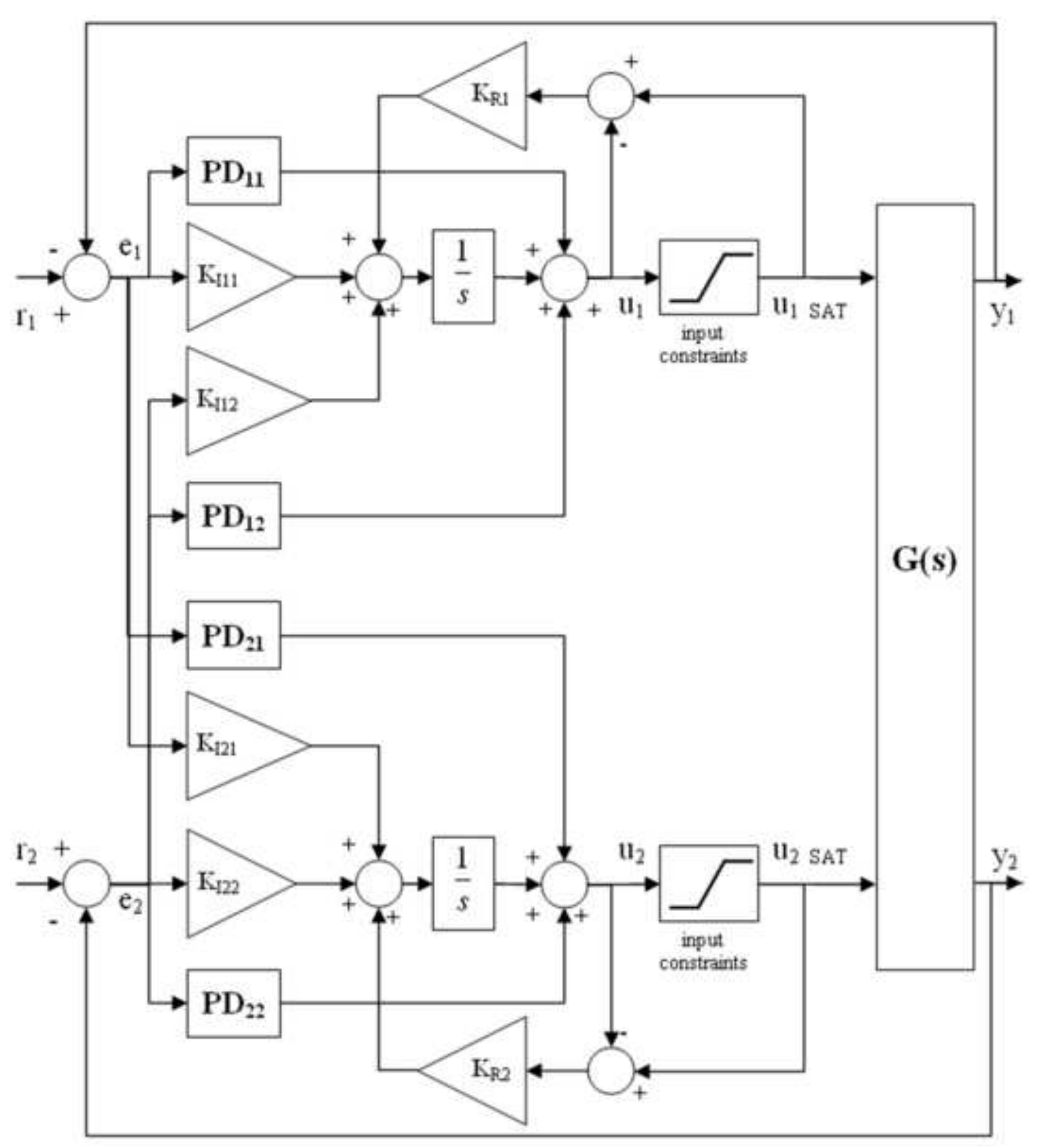

Figure 4. Anti-windup scheme for a multivariable PID controller 

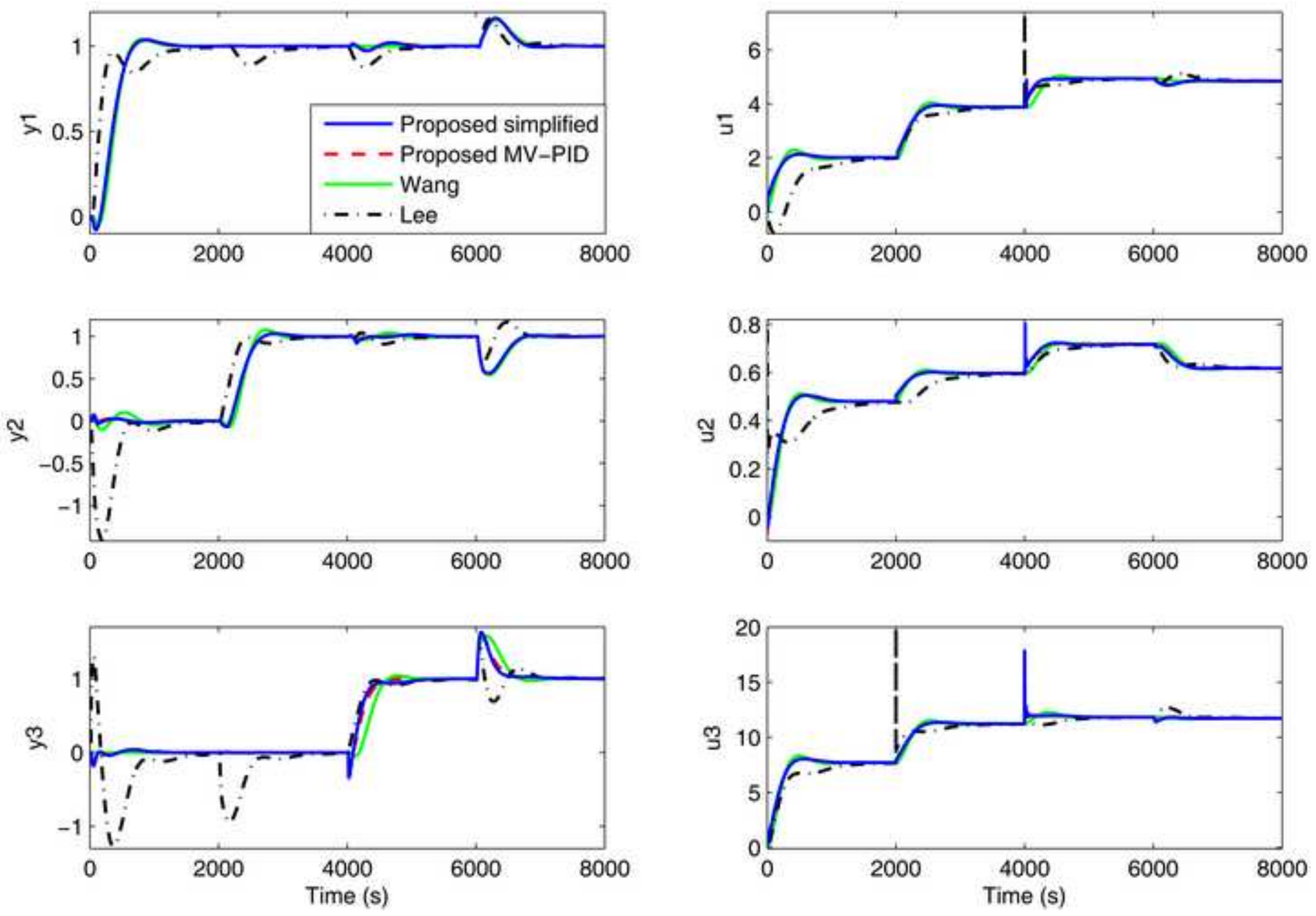

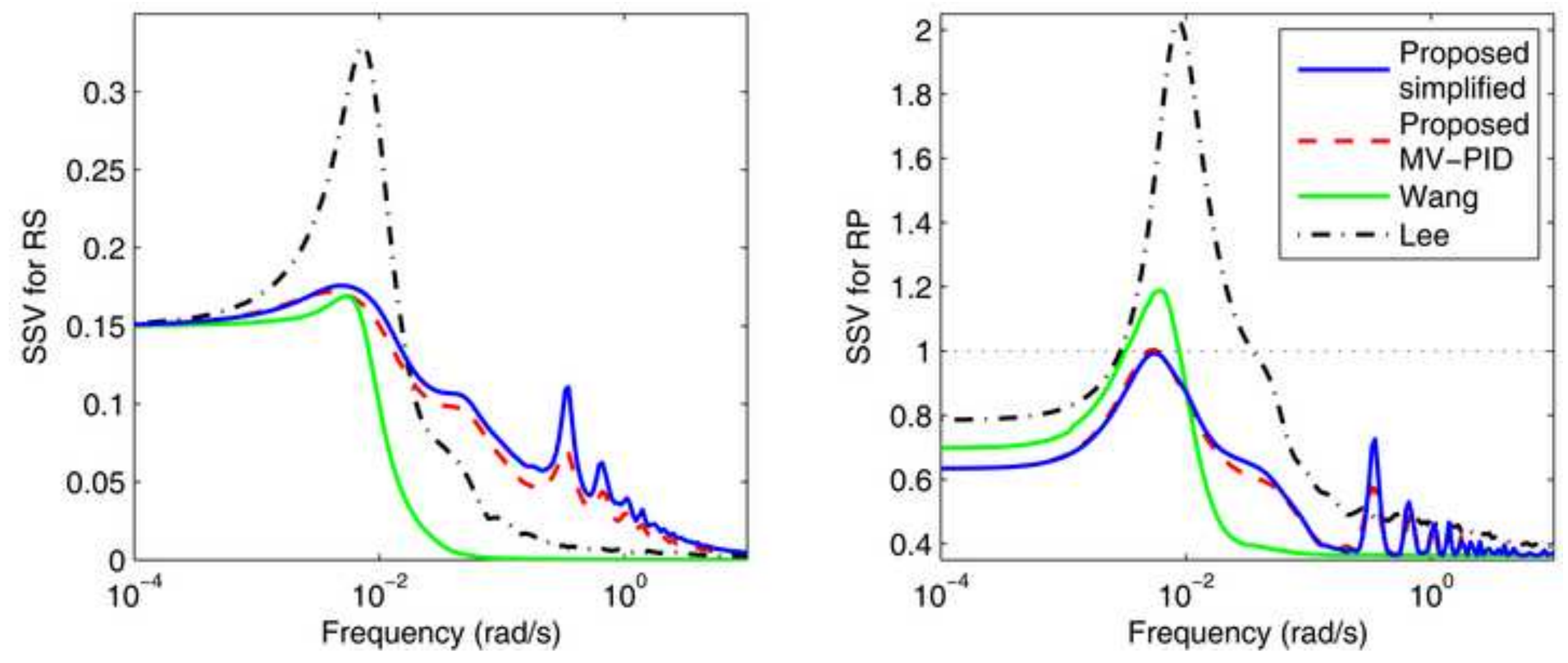

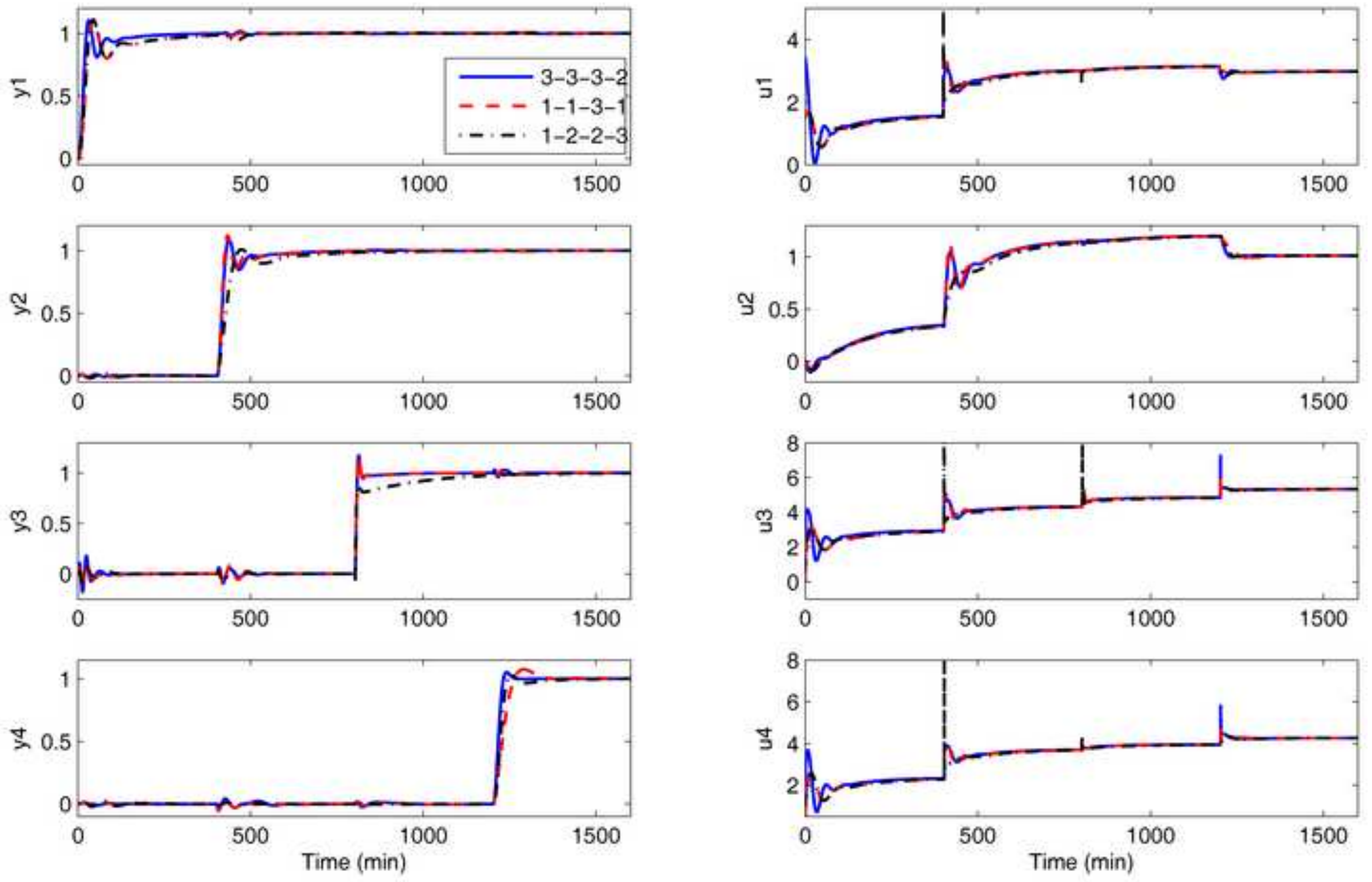

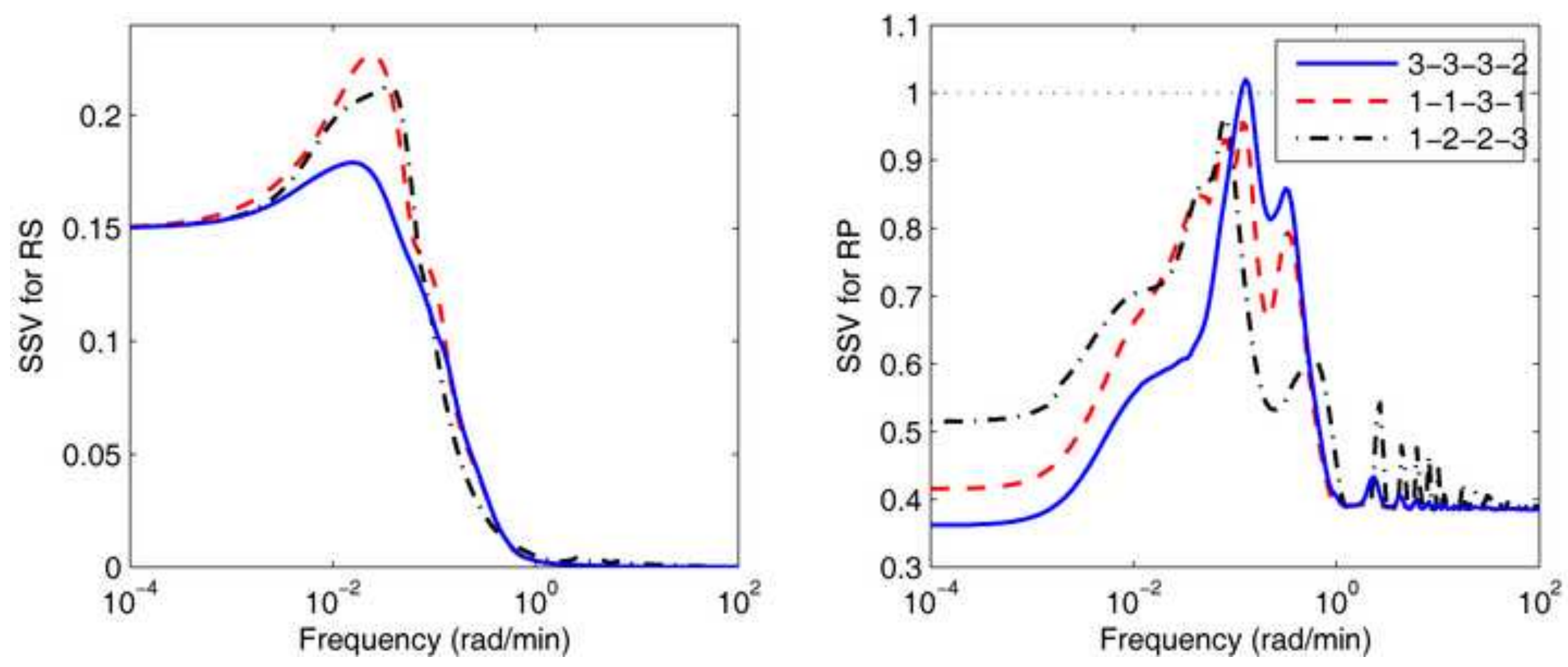
Figure 9. Step response in example 3 colour
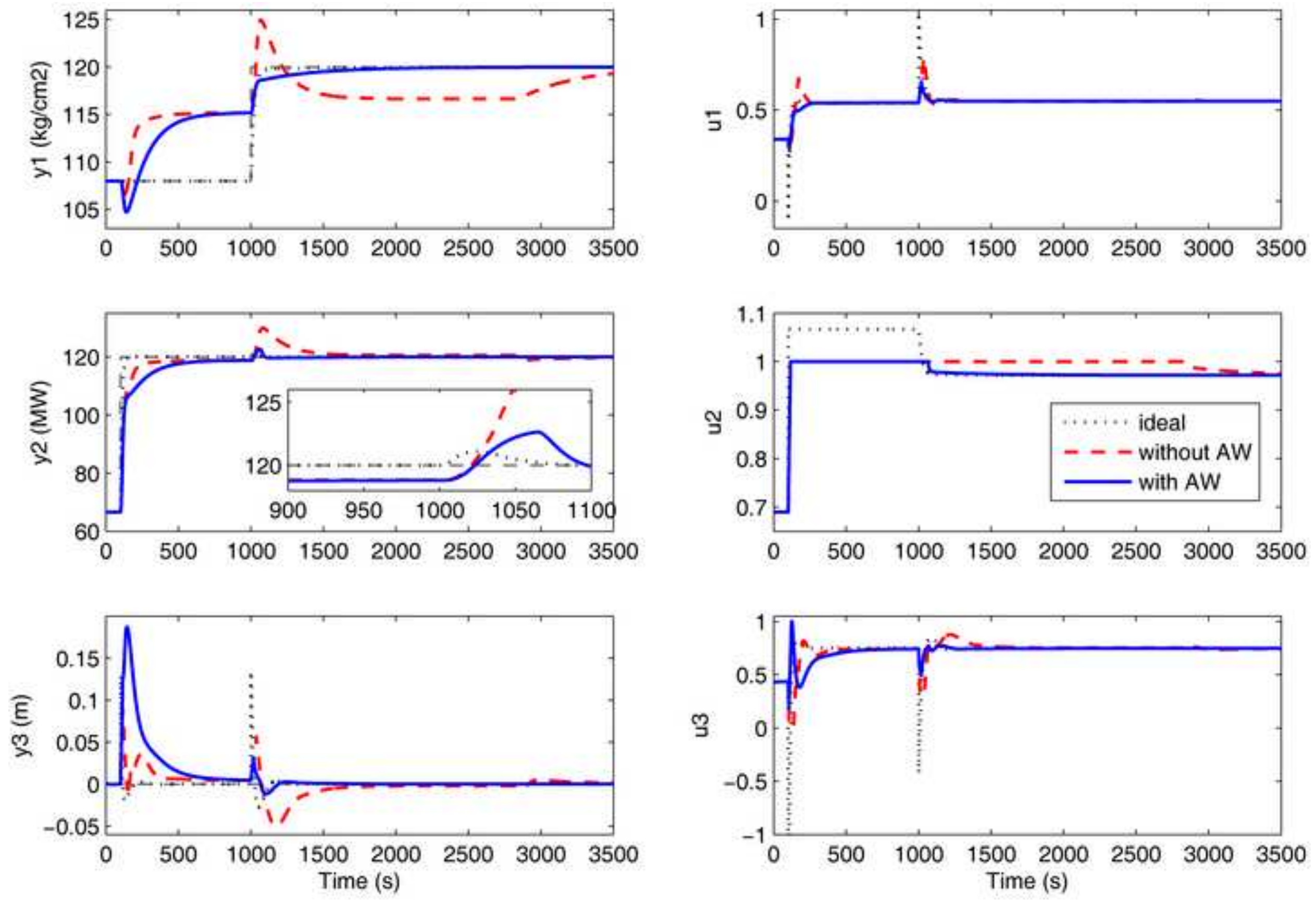

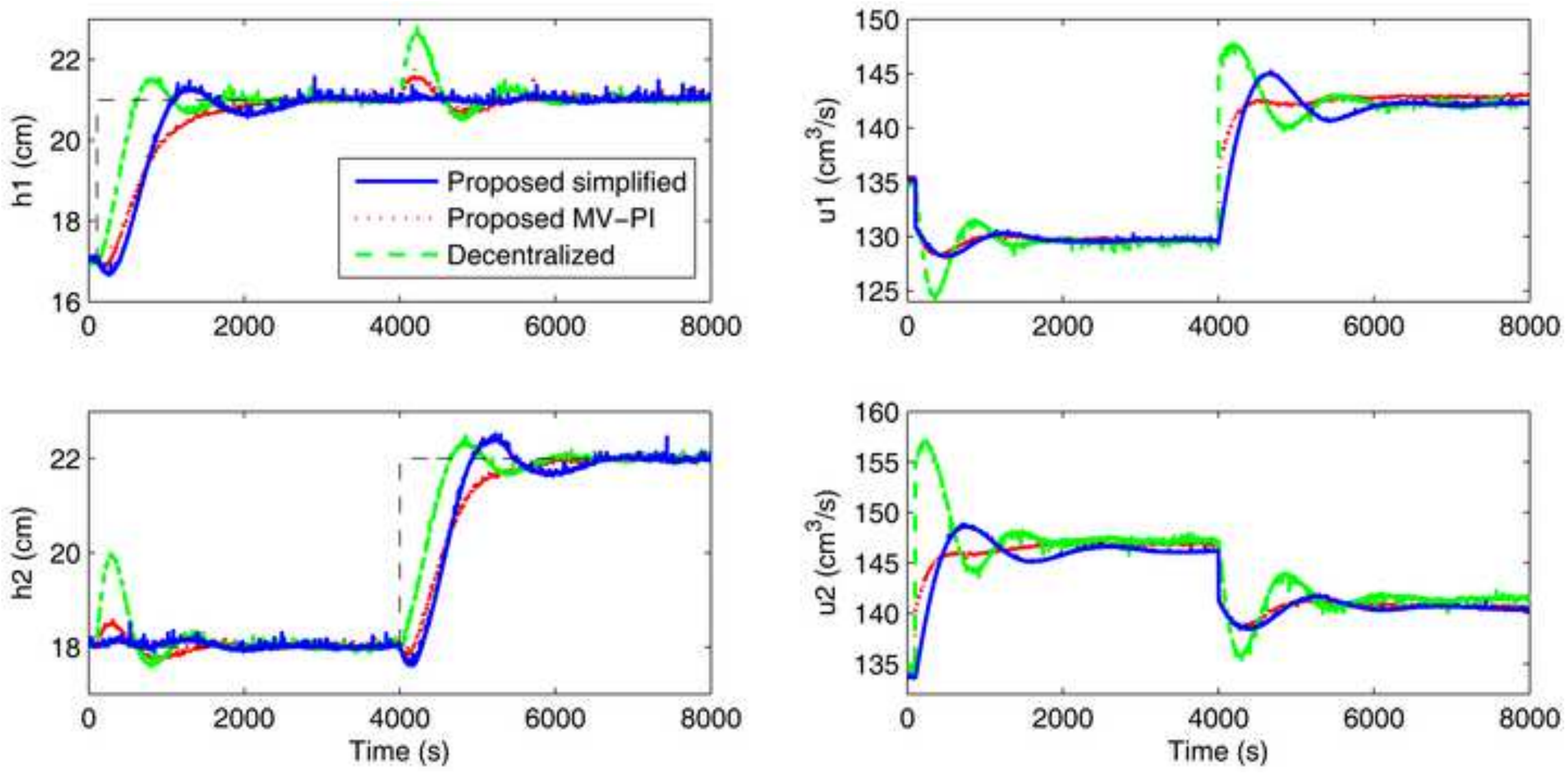